\title{
Rock physics modelling for determination of effective elastic properties of the lower Paleozoic shale formation, North Poland
}

\author{
Kamila Wawrzyniak-Guz ${ }^{1}$ (D)
}

Received: 9 May 2019 / Accepted: 3 September 2019 / Published online: 7 September 2019

(C) The Author(s) 2019

\begin{abstract}
This paper presents an application of rock physics templates constructed with the use of the granular effective medium theory and the shale model to estimate the elastic properties of the Silurian and Ordovician shale formations from the Baltic Basic, Poland. The author uses available logging data from three nearby wells and their petrophysical interpretation to distinguish various lithologies and to determine average matrix mineral composition of each lithology group, essential in further rock physics modelling. Anisotropy estimation and investigation of the relation between various petrophysical parameters precede the rock physics modelling. The logging data cross-plotted in $V p / V s$ ratio-acoustic impedance domain reveals distinct compaction trend for shales, which is not followed by shales with increased organic matter and calcareous deposits. These two lithology groups present own trends, which are related to increasing kerogen and carbonate minerals contents, respectively. The trends are the subject of rock physics modelling. Granular effective medium rock physics templates are constructed for each lithology group. The rock physics analyses reveal that the elastic properties of strongly compacted shales, including shales with organic matter, might be successfully described by the lower modified Hashin-Shtrikman bound, which is useful in compaction trend modelling. Marly deposits can be modelled in a similar way to shales. The upper modified HashinShtrikman bound provides a better template for carbonates as it models the cementation process. The shale model provides independent rock physics template for shales. Comparison of these two approaches shows that the granular effective medium method better describes the elastic properties of the analysed formations. The paper includes also the proposition of the final rock physics template constructed for the Silurian and the Ordovician formation from the Baltic Basin that can contribute to a better understanding of the elastic properties of the lower Paleozoic shale plays in Poland.
\end{abstract}

Keywords Rock physics template $\cdot$ Shale gas $\cdot$ Baltic Basin $\cdot$ Elastic properties

\section{Introduction}

Rock physics studies the relationship between physical and elastic properties of rocks to better understand relations between geophysical measurements and rock properties. It emphasis velocity data in general (seismic, sonic logs, or ultrasonic measurements) combined with reservoir properties such as porosity, density, saturation, and clay volume derived from well logs and (or) seismic inversion. Well logging data are the base for creating a rock physics model and necessary in its proper calibration to seismic data. Linking

Kamila Wawrzyniak-Guz

wawrzyni@agh.edu.pl

1 Department of Geophysics, Faculty of Geology, Geophysics and Environmental Protection, AGH University of Science and Technology, al. Mickiewicza 30, 30-059 Kraków, Poland rock and fluid properties to velocities is a basis of quantitative seismic interpretation and allows better understanding seismic response: the seismic reflections are generated by the contrast of acoustic impedance, which is a product of velocity and density. Rock physics relations are usually quantified in terms of elastic moduli, later used for velocity computation.

Rock physics models try to approximate geological processes and deal with the complexity of nature. Firstly, earth materials are inherently heterogeneous. In theory, we make the simplifying assumption that the heterogeneous rocks have some effective, i.e. averaged homogeneous properties over the scale of the measurements. The material can be considered homogenous if its constituents are smaller than the wavelength of measurements. In rock physics modelling, we need to define effective elastic moduli, which depend on (1) elastic moduli of the components, (2) their volume fractions, 
and (3) their geometrical relationships. If only (1) and (2) are known, then one can predict for the composite only the upper and lower bounds of the elastic properties. The precise values of moduli depend on the geometrical details how the components are arranged relative to each other. However, the upper and lower bounds of the moduli are robust and relatively free of approximations limits of the elastic behaviour and are wildly used in rock physics. Assuming the geometrical arrangement of the rock constituents, one can apply some models that approximate the rock elastic moduli. Popular approaches include approximation of the rock by the collection of separate grains, whose elastic properties are determined by the deformability and stiffness of their grain-to-grain contacts, and the description of the rock as an elastic solid containing cavities (inclusions) representing the pore space. Most of the contact models are based on the Hertz-Mindlin theory developed by Hertz (1882) and Mindlin (1949) who described the elastic behaviour of two identical spheres in contact. Granular effective medium (GEM) models are a good approximation of sedimentary rocks made of an aggregate of round grains, such as sandstones or ooidal limestone. However, they are often applied to clay-rich or shaly sandstones and even to shales. The inclusion models, for example Kuster and Toksöz (1974) model, assume "penny-shape" cavities that reduce the overall stiffness of the rock. Shales, due to the strong alignment of clay minerals, require a different approach to model elastic properties. Vernik and Kachanov (2010) proposed a semiempirical relation between bedding-normal stiffness (or bedding-normal $P$-velocity) and porosity formulated for fully water-saturated conventional shales. Bedding-normal $S$-velocity is computed using the nonlinear semiempirical equation derived from $V p-V s$ relation. The shale model (SM) is willingly applied by many authors to rock physics models of shales (e.g. Mur and Vernik 2019; Sayers and Dasgupta 2019; Vernik 2016). An excellent introduction to rock physics models and their application to seismic interpretation can be found in Avseth et al. (2010) and Vernik (2016). A concise set of theoretical and empirical relations of rock physics is presented in a handbook of Mavko et al. (2011). Mur and Vernik (2019) published a brief overview of the most popular rock physics models, and Allo (2019) summarised the granular effective medium models that are widely applied in rock physics and seismic petrophysics.

Ødegaard and Avseth (2004) proposed a technique called rock physics template (RPT), in which the fluid and the mineralogical content of a reservoir could be estimated on a cross-plot of $V p / V s$ ratio against acoustic impedance (AI) of $P$-wave. Relationships between elastic wave velocities and porosity or density of the formation are also frequently used in many rock physics models. Successful RPT should be made for specific sedimentary basin or area and calibrated for specific rock types with the use of appropriate rock physics models. This ensures taking into account local geological parameters such as lithology and mineralogy, reservoir properties, i.e. porosity, fluid type and saturation, pressure, temperature gradient, and diagenesis. The templates may be used for interpretation of seismic data away from the boreholes or for the corresponding sedimentary basin with similar lithology.

Most of the RPT has been created for siliciclastic rocks. There have been numerous researches conducted for sands, sandstones, and shales providing the essential relationships between lithology, fluid, and elastic rock properties as well as studying depositional and compactional trends. For example, Avseth et al. (2001) studied the effect of burial and compaction on the seismic properties of unconsolidated sands and shales, and the cemented sandstones from the North Sea, while Bredesen et al. (2019) performed rock physics modelling conditioned by the burial history of the Barents Sea sandstones. Geologically consistent depth trend modelling that accounts for burial, pressure and temperature history was proposed by Dræge (2019). Chi and Han (2009) analysed unconsolidated sands from the Gulf of Mexico. Avseth et al. (2009) presented how the rock texture, geological depositional environment and compaction in reservoir sandstones could be diagnosed from rock physics models of elastic moduli or velocities versus porosity cross-plots. Narongsirikul et al. (2019) applied soft-sand model, established for normally compacted sediments, to mechanically compacted over consolidated sandstones receiving insight into pre-consolidation stress estimation. A general rock physics template derived entirely from the well logging data, generated for sand and shale lithologies for Vienna Basin, Austria, and supplemented with the carbonate bounds, was published by Tucovic and Gegenhuber (2017).

Besides the rock physics templates for siliciclastic sediments, the rock physics modelling has been done for carbonates reservoir too. Multi-scale rock physics templates based on laboratory, well logs, and seismic data were created by Ba et al. (2013). Gegenhuber and Pupos (2015) determined rock physics templates for the carbonates in Austria on the basis of laboratory measurements. Xu and Payne (2009) tested some originally designed for clastic rocks models and adjusted them to the complex pore system in carbonates.

Recently, the rock physics of the unconventional hydrocarbon reservoirs has been extensively developed. The studies are concentrated on clays, shales, and organic-rich shales; however, they include also tight gas sandstones, coals and coal bed methane, heavy oil, and gas hydrates (Prasad et al. 2009). Robust rock physics modelling for clay-rich source rocks is presented in Carcione and Avseth (2015). Analysis of organic-rich shales from the North Shelf can be found in Avseth (2014) and Avseth and Carcione (2015). A significant impact of kerogen on elastic properties and seismic responses of shales was studied by Carcione et al. (2011) 
and Vernik and Milovac (2010) who compared rock physics models for organic-rich shales. Sayers (2013) calculated the effect of kerogen on the anisotropy of shales. Rock physics model for organic-rich shales to quantify the impact of kerogen content and kerogen porosity was constructed by Li et al. (2015).

Recognition of elastic properties of Polish shales is still in progress. For example, shaly-sandy Miocene and lower Paleozoic shale formations were modelled by Bała (2007, 2015, 2017) using Biot-Gassmann and Kuster-Toksöz theoretical relationships. Stadtmüller et al. (2018) computed matrix bulk moduli for Ordovician and Silurian shales from the Baltic Basin based on the correlation between static moduli from laboratory measurements and the volume fractions of the mineral constituents. Elastic and reservoir properties of shale gas formation investigated by seismiclike attributes derived from full sonic logs were studied by Wawrzyniak-Guz (2018). Brittleness index based on elastic properties of Ordovician and Silurian shales from the Baltic Basin was calculated by Bała Jarzyna et al. (2017a), Liana and Papiernik (2017) and Cyz et al. (2018). Method of resolution enhancement of seismic data to aid structural interpretation of sweet spots within seismically thin formations in the Baltic Basin was proposed by Kwietniak et al. (2018).

The primary objective of this paper is to apply two common approaches in rock physics modelling to the shale formations from the Baltic Basin. The first method is based on the granular effective medium (GEM) theory, which is extensively used for different rock types such as unconsolidated, cemented and compacted, and clay-rich sediments. The second one, the shale model (SM), is valid for conventional fully water-saturated shales. Before the modelling of the elastic properties, I made the data-driven lithology discrimination based on logs and their petrophysical interpretation. It allowed me to distinguish three lithology groups: shales, shales with increased organic matter, and carbonates and calcareous deposits, as well as to determine the average mineral matrix composition used in further computations for each lithology individually. Then, I attempted to estimate the anisotropy of shales with the use of pseudo-anisotropy Thomsen parameters derived from the logging data. Then, I used $V p / V s$ ratio-acoustic impedance and $V p$-total porosity cross-plots to examine the relationships between petrophysical properties of the rocks. The cross-plots revealed also a distinct compaction trend for shales, and separate trends for shales with increased organic matter and calcareous deposits, which are related to increasing kerogen and carbonate minerals contents, respectively. These trends were the subject of following rock physics modelling. The GEM rock physics templates were constructed for each distinguished lithology group; the SM templates were constructed for shales only. The lower modified Hashin-Shtrikman bound, that was used in the GEM method, reasonably described compaction trend for shales, shales with increased organic matter, and marls. For carbonates, the modified upper Hashin-Shtrikman bound performed better. The SM method gave unsatisfactory results for shales, especially for very low porosities. In the end, I proposed the final rock physics templates for various lithologies of lower Paleozoic formations from Baltic Basin.

\section{Geological information}

In Poland, the lower Palaeozoic shale formations spread along the western margin of the East European Platform. They have been considered as one of the most interesting unconventional hydrocarbon systems in Poland. The sedimentary basins include the Baltic Basin in the north, the Podlasie Basin in the middle part, and the Lublin Basin in the south-eastern part of Poland (Poprawa 2010; Porębski et al. 2013; Podhalańska et al. 2016). The recent shale gas exploration boom in Poland has resulted in many researches focused on investigation and understanding of the complex petrophysical, geomechanical, and reservoir properties of unconventional resources in Poland, particularly shale plays (e.g. Podhalańska 2016; Jarzyna et al. 2017a, b, 2018; Malinowski et al. 2018).

This paper presents the analysis of the Silurian and Ordovician shale deposits from the Baltic Basin, recognised as the basin with the high hydrocarbon potential, carried out for three closely located boreholes. The study included the following lithostratigraphic units:

- $\quad P u$ Fm Puck Claystone and Marly Claystone Formation (Silurian, Pridoli, Ludlow),

- Ko Fm Kociewie Claystone and Mudstone Formation (Silurian, Ludlow),

- $\operatorname{Re} M b$ Reda Calcareous Mudstone Member, Kociewie Formation (Silurian, Ludlow),

- Pe Fm Pelplin Claystone Formation (Silurian, Ludlow, Wenlock),

- $\quad \mathrm{Pa}$ Fm Pasłek Claystone Formation (Silurian, Llandovery),

- Ja Mb Jantar Bituminous Black Claystone Member, Pasłęk Formation (Silurian, Llandovery),

- Pr Fm Prabuty Marl and Claystone Formation (Ordovician, Ashgill),

- $S a$ Fm Sasino Claystone Formation (Ordovician, Caradoc, Llanvirn),

- Ko Fm Kopalino Limestone Formation (Ordovician, Llanvirn, Arenig).

The lithostratigraphic division is presented after (Modliński and Szymański 1997; Modlliński et al. 2006; Podhalańska et al. 2016). Jantar Member and Sasino 
Formation are considered as series with high hydrocarbon potential due to zones of increased kerogen volume. However, they are relatively thin series of deposits. The thickness of Ja $\mathrm{Mb}$ ranges from $11 \mathrm{~m}$ in well $\mathrm{W} 2$ to $14 \mathrm{~m}$ in W3 well, and the thickness of the Sa Fm ranges from $19.5 \mathrm{~m}$ in well $\mathrm{W} 3$ to $25.5 \mathrm{~m}$ in well $\mathrm{W} 1$.

Analysed deposits are dominated by claystones, siltstones, and mudstone (Ko Fm, Pe Fm, Pa Fm), which are locally enriched in organic matter ( $\mathrm{Ja} \mathrm{Mb}$ and $\mathrm{Sa} \mathrm{Fm}$ ). Some sediments are marly (Pu Fm and Pr Fm). There are also carbonates and calcareous deposits ( $\mathrm{Re} \mathrm{Mb}$ and Ko Fm). The clay groundmass of the shales is composed mainly of illite with the admixture of illite/smectite mixed layer structures and chlorite. The silt fraction consists of quartz with addition of feldspars. Quartz and carbonates form the cement in the rocks. Carbonates are present also as thin intercalations, concretion-like concentrations, and laminae. Organic matter may be scattered or concentrated in grains or laminae. There are bentonite and tuff intercalations present in some formations as well as pyrite, other sulphur compounds and phosphates (Sikorska-Jaworowska et al. 2016; Feldman-Olszewska and Roszkowska-Remin 2016).

Data used in the study are wireline $\log$ s that were recorded in three nearby wells: W1, W2, and W3. The line of correlation goes from WSW to ENE between W1 and W2 wells and from NNW to SSE between W2 and W3 wells. The distances between wells are $5.26 \mathrm{~km}$ and $18.55 \mathrm{~km}$, respectively. The depth of the analysed deposits ranges from approximately $1000-3000 \mathrm{~m}$. Figure 1 presents the depth intervals and lithostratigraphic division that are examined in the study.

The well logging data used in this study come from the standard measurements of gamma, spectral gamma, density, neutron, and resistivity logs as well as from geochemical and cross-dipole sonic logs. The measurements were taken with the use of the Halliburton and Schlumberger logging tools. The logging services provided the petrophysical, lithologi$\mathrm{cal}$, and reservoir interpretation of the data. It was later supplemented with additional interpretation when the laboratory tests on core data had been completed. Results of the formation evaluation in each well, including mineral composition and TOC evaluation (by the Passey et al. 1990 method), porosity and saturation, were allowed in this research.

Selected petrophysical properties of the lower Paleozoic sediments derived from well logging data for $\mathrm{W} 1, \mathrm{~W} 2$, and W3 wells are summarised in Table 1 . The table presents the minimum, maximum, and average values of $P$-wave and $S$-wave velocities ( $V p$ and $V s, \mathrm{~m} / \mathrm{s}$ ), bulk density (RHOB, $\mathrm{kg} / \mathrm{m}^{3}$ ), total porosity (PHIT, \%), wet clay volume ( $V \mathrm{cl}, \%$ ), kerogen volume (VKER, \%), and hydrocarbon saturation $\left(V_{\mathrm{GAS}}, \%\right)$ for the lithostratigraphic units.

To visualise relations between the petrophysical parameters, $P$-wave velocity $(V p)$ is cross-plotted in a function of total porosity (PHIT) and presented in Fig. 2. The points are coloured regarding the lithostratigraphic series (a), clay volume (b), bulk density (c), carbonate (d), kerogen (e), and hydrocarbon (f) volumes. The figure shows the data only from well $\mathrm{W} 1$; however, similar relations are observed in the $\mathrm{W} 2$ and $\mathrm{W} 3$ wells.
Fig. 1 Lithostratigraphic units and depth intervals of investigated formations in wells $\mathrm{W} 1$, W2 and W3

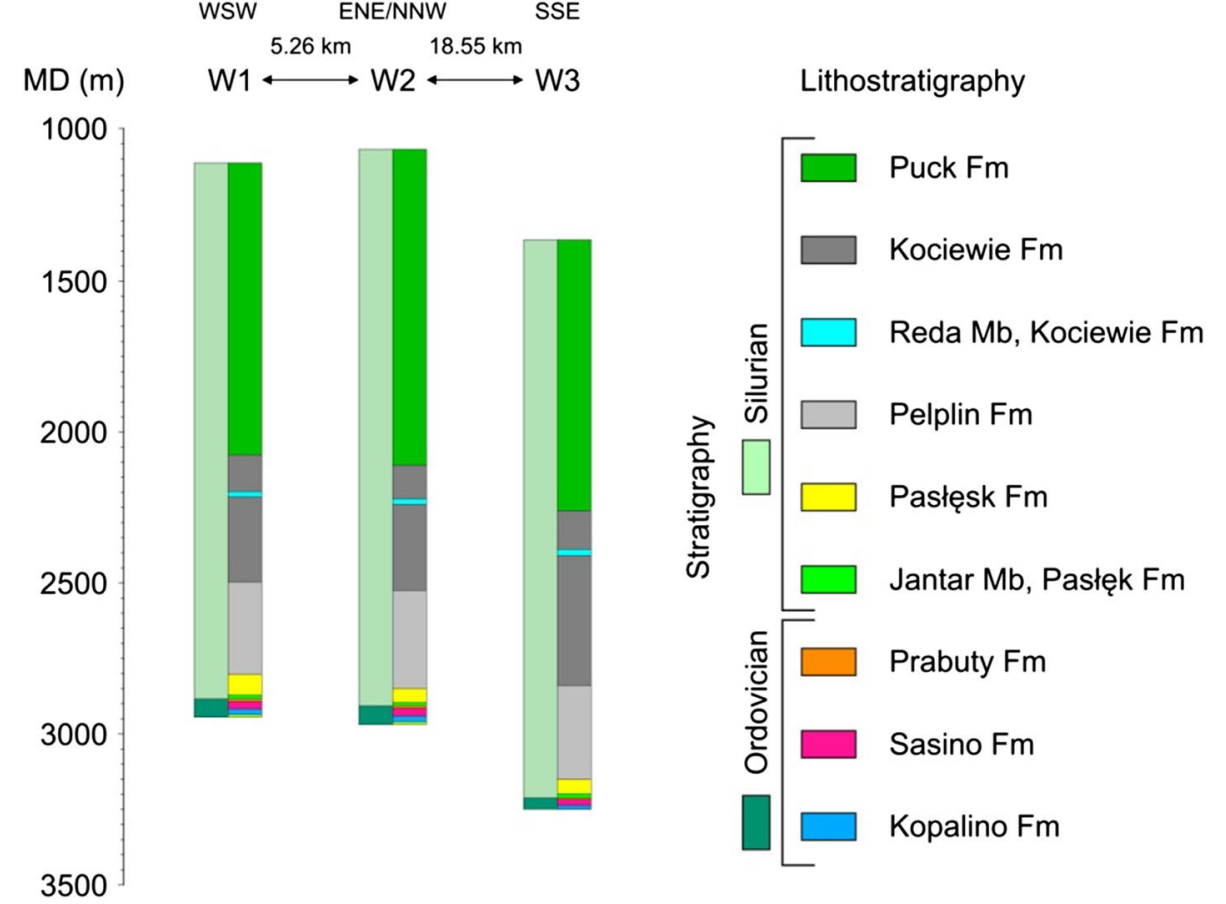


Table 1 Basic statistics of petrophysical properties of the lower Paleozoic formations from $\mathrm{W} 1, \mathrm{~W} 2$ and W3 wells: $V p, V s-P$ - and $S$-wave velocities, PHITtotal porosity, RHOB-bulk density, $V_{\mathrm{CL}}$-wet clay volume, $V_{\mathrm{KER}}$ - kerogen volume, $V_{\mathrm{GAS}}$ hydrocarbon volume

\begin{tabular}{|c|c|c|c|c|c|c|c|c|c|c|c|c|c|c|}
\hline \multirow[t]{4}{*}{ Litho-strat. } & \multicolumn{14}{|c|}{ Wells: W1, W2, W3 } \\
\hline & \multicolumn{2}{|c|}{$V p(\mathrm{~m} / \mathrm{s})$} & \multicolumn{2}{|c|}{$V s(\mathrm{~m} / \mathrm{s})$} & \multicolumn{2}{|c|}{ PHIT (\%) } & \multicolumn{2}{|c|}{$\begin{array}{l}\mathrm{RHOB} \times 10^{3} \\
\left(\mathrm{~kg} / \mathrm{m}^{3}\right)\end{array}$} & \multicolumn{2}{|c|}{$V_{\mathrm{CL}}(\%)$} & \multicolumn{2}{|c|}{$V_{\mathrm{KER}}(\%)$} & \multicolumn{2}{|c|}{$V_{\mathrm{GAS}}(\%)$} \\
\hline & Min & Max & Min & Max & Min & $\operatorname{Max}$ & Min & $\operatorname{Max}$ & Min & $\operatorname{Max}$ & Min & Max & Min & Max \\
\hline & $\mathrm{Av}$ & & Av & & $\mathrm{Av}$ & & Av & & $\mathrm{Av}$ & & Av & & $\mathrm{Av}$ & \\
\hline \multirow[t]{2}{*}{ Pu Fm } & 2891 & 4297 & 1301 & 2362 & 3.9 & 17.6 & 2.11 & 2.72 & 40.9 & 93.1 & 0.0 & 3.5 & 0.0 & 2.4 \\
\hline & 3385 & & 1769 & & 10.4 & & 2.61 & & 68.3 & & 0.5 & & 0.1 & \\
\hline \multirow[t]{2}{*}{$\mathrm{Kc} \mathrm{Fm}$} & 3435 & 5025 & 1665 & 2843 & 2.3 & 12.3 & 2.55 & 2.75 & 32.8 & 89.7 & 0.0 & 2.9 & 0.0 & 2.1 \\
\hline & 4002 & & 2138 & & 6.9 & & 2.69 & & 62.0 & & 0.7 & & 0.2 & \\
\hline \multirow[t]{2}{*}{$\mathrm{Re} \mathrm{Mb}$} & 3864 & 5185 & 1979 & 2736 & 2.5 & 8.9 & 2.64 & 2.74 & 18.9 & 73.3 & 0.0 & 1.3 & 0.0 & 2.6 \\
\hline & 4555 & & 2451 & & 5.4 & & 2.69 & & 36.3 & & 0.3 & & 0.5 & \\
\hline \multirow[t]{2}{*}{ Pe Fm } & 3779 & 5250 & 2124 & 2870 & 2.5 & 10.3 & 2.55 & 2.76 & 28.7 & 87.6 & 0.0 & 4.2 & 0.0 & 3.2 \\
\hline & 4306 & & 2488 & & 5.5 & & 2.69 & & 61.4 & & 1.8 & & 0.2 & \\
\hline \multirow[t]{2}{*}{$\mathrm{Pa} \mathrm{Fm}$} & 3621 & 4403 & 1863 & 2519 & 3.4 & 10.1 & 2.60 & 2.77 & 40.9 & 94.8 & 0.0 & 6.2 & 0.0 & 3.1 \\
\hline & 4079 & & 2239 & & 6.4 & & 2.70 & & 72.1 & & 0.9 & & 0.4 & \\
\hline \multirow[t]{2}{*}{$\mathrm{Ja} \mathrm{Mb}$} & 3298 & 4352 & 1871 & 2529 & 2.2 & 11.6 & 2.45 & 2.74 & 39.6 & 89.4 & 1.3 & 15.8 & 0.0 & 6.0 \\
\hline & 3638 & & 2081 & & 6.7 & & 2.58 & & 69.6 & & 6.8 & & 1.7 & \\
\hline \multirow[t]{2}{*}{ Pr Fm } & 3715 & 5029 & 2095 & 2863 & 2.2 & 8.9 & 2.56 & 2.78 & 28.1 & 83.5 & 0.0 & 5.6 & 0.0 & 4.2 \\
\hline & 4398 & & 2533 & & 5.6 & & 2.70 & & 51.8 & & 0.9 & & 1.3 & \\
\hline \multirow[t]{2}{*}{$\mathrm{Sa} \mathrm{Fm}$} & 3489 & 5479 & 1630 & 3153 & 1.2 & 13.2 & 2.41 & 2.85 & 22.3 & 83.4 & 0.0 & 15.0 & 0.0 & 7.2 \\
\hline & 3790 & & 2218 & & 7.4 & & 2.57 & & 56.3 & & 5.3 & & 2.4 & \\
\hline \multirow[t]{2}{*}{ Ko Fm } & 4338 & 5847 & 2370 & 3277 & 0.7 & 7.2 & 2.66 & 2.78 & 4.5 & 68.0 & 0.0 & 4.5 & 0.0 & 3.3 \\
\hline & 5220 & & 2819 & & 3.1 & & 2.71 & & 28.6 & & 0.3 & & 0.4 & \\
\hline
\end{tabular}

$P$-wave velocity of the investigated sediments ranges roughly between 3000 and $5500 \mathrm{~m} / \mathrm{s}$. Porosity of the lower Paleozoic deposits is low (Krakowska and Puskarczyk 2015), from a few to several per cent (Table 1). There is a stable, monotonic, and slightly nonlinear relationship between $V p$ and PHIT: the increase in porosity results in decreased $P$-wave velocity. It can be noticed that the formations composed of claystones, mudstones, and siltstones exhibit compaction effect: the deeper the formation is, the lower the porosity and the higher the velocity it has. The compaction is observed especially for Prabuty, Pasłęk, Pelplin, Kociewie, and Puck Formations (Fig. 2a). The points for these formations overlap as a consequence of various ranges of velocities and porosities. As expected, the highest values of $P$-wave velocity have calcareous mudstones of Reda Member and limestones of Kopalino Formation. Re Mb and Ko Fm are also characterised by the lowest porosity and clay content, the highest bulk density, and the highest carbonate minerals volume (Fig. 2b-d, respectively). Jantar Member and Sasino Formation, which are considered as potential sweet spots, have distinct petrophysical characteristics, and the points on the cross-plot are shifted from the compaction trend towards lower velocities and higher porosities. These two series are characterised by relatively moderate velocities and porosities compared to the other formations. Average values of $V p$ and PHIT are (Table 1): $3638 \mathrm{~m} / \mathrm{s}$ and $6.7 \%$ (Ja
$\mathrm{Mb}$ ) and $3790 \mathrm{~m} / \mathrm{s}$ and 7.4\% (Sa Fm). There are also zones of elevated organic matter and saturated with hydrocarbons within the shales of $\mathrm{Ja} \mathrm{Mb}$ and $\mathrm{Sa} \mathrm{Fm}$ sediments (Fig. 2e and $\mathrm{f}$ ), characterised by the higher kerogen volume that was confirmed by the TOC laboratory measurements (Kotarba et al. 2014; Jarzyna et al. 2017b, 2018). Increased kerogen volume corresponds also to lower bulk density (Fig. 2c, Table 1). For shales composed of claystones, mudstones, and siltstones, it can be seen that the increase in clay volume has a greater influence on the decrease in $P$-wave velocity rather than porosity (Fig. 2b): for any formation, the lowest velocity is observed for the highest clay content.

\section{Anisotropy evaluation of the lower Paleozoic deposits}

Shales, which are major components of sedimentary basis, play an important role in elastic wave propagation because of their anisotropic microstructure. The inorganic phase of shales is typically composed of various minerals consisting of quartz, feldspar, pyrite, calcite, and dolomite as well as clay minerals that may include chlorite, illite, kaolinite, and smectite. Clay minerals have a strongly layered structure resulting in elastic anisotropy. Because anisotropic clay minerals tend to be partially aligned with the bedding plane (e.g. 
(a)

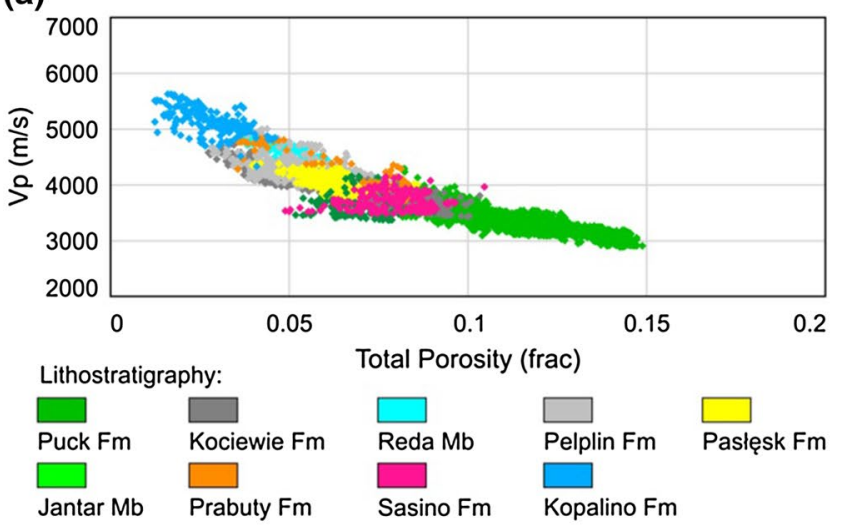

(c)

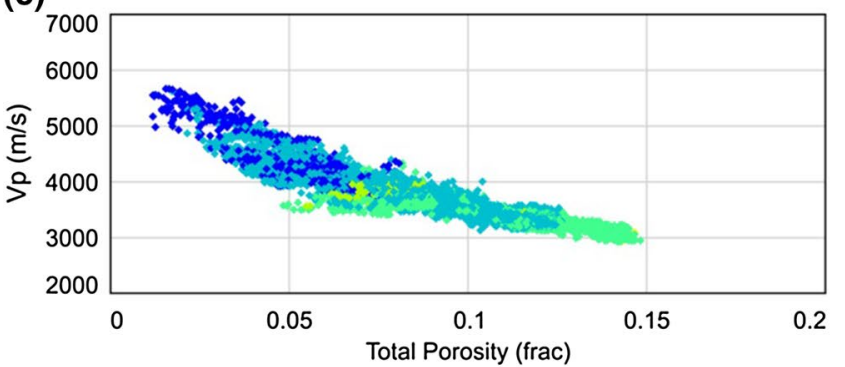

2.3

Bulk Density * $10^{3}\left(\mathrm{~kg} / \mathrm{m}^{3}\right)$

(e)

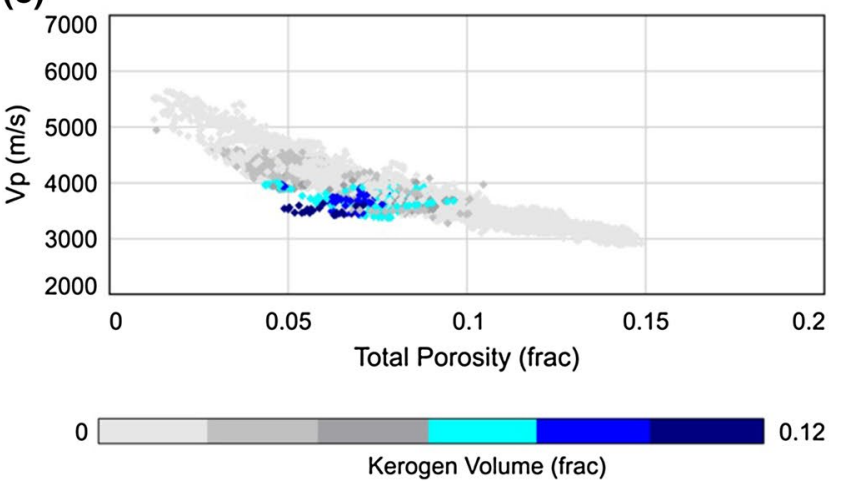

(b)

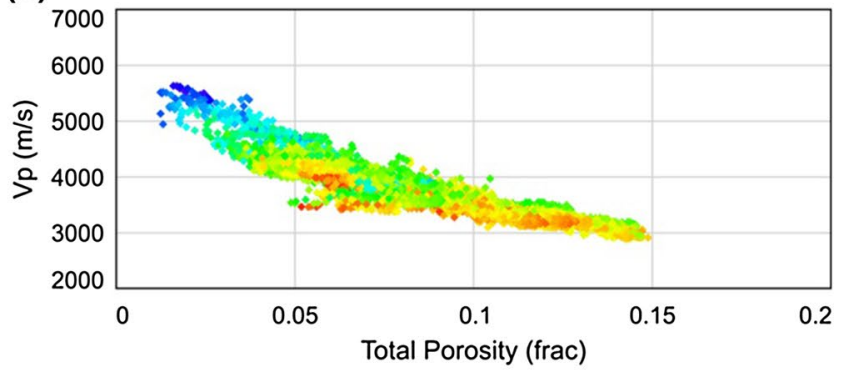

0

(d)

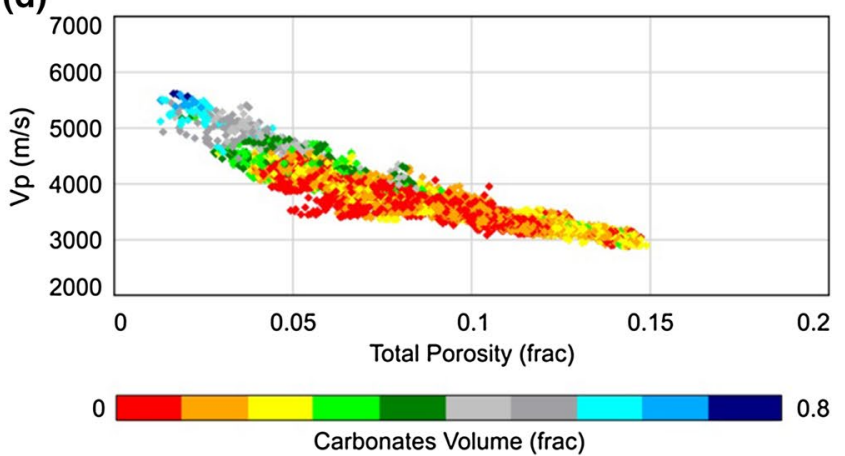

(f)

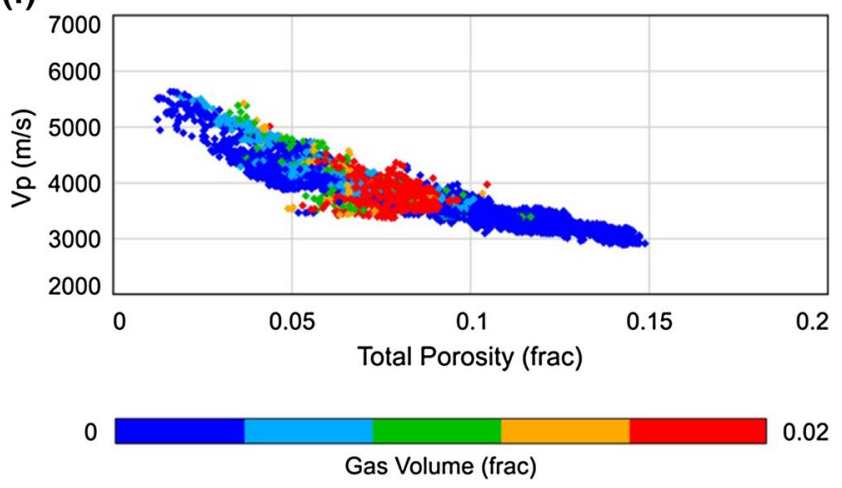

Fig. $2 \mathrm{Vp}$-PHIT cross-plots as a function of lithostratigraphic divisions (a), clay volume (b), bulk density (c), carbonate (d), kerogen (e), and hydrocarbon (f) volumes-logging data from well W1

Sayers 1994, 2005; Sengupta et al. 2015; Sayers and den Boer 2016), shales (even conventional) are often elastically anisotropic. For clay-rich shales, anisotropy caused by the alignment of clay minerals and microlaminations is visible in scanning electron images. Anisotropy may be caused also by laminations at larger scales. Unconventional, organic-rich shales contain additionally organic components. They are often found to be strongly anisotropic due to the presence of anisotropic clay minerals as well as the bedding-parallel lamination of organic material within the shale, which is caused by the partial alignment of kerogen inclusions and pores in the rock (e.g. Vernik and Liu 1997; Vernik and Milovac 2010; Sayers 2013; Carcione and Avseth 2015; Zhao et al. 2016). Nonrandomly orientations of microcracks, alongside small-scale inter-layering and preferred orientation of kerogen and plate-like clay, are the third cause of elastic anisotropy in organic shales (e.g. Vernik and Nur 1992; Vernik 1993).

Shale in its nonfractured state is often assumed to be polar anisotropic (or transversely isotropic, TI) with a vertical axis of rotational symmetry (Thomsen 2012). A TI medium has a hexagonal symmetry with five independent 
elastic stiffnesses (Mavko et al. 2011). Assuming the $x_{3}$ axis lies along the axis of rotational symmetry, the nonvanishing elastic stiffness coefficients are: $c_{11}=c_{22}, c_{33}, c_{12}=c_{21}$, $c_{13}=c_{31}=c_{23}=c_{32}, c_{44}=c_{55}$, and $c_{66}=\left(c_{11}-c_{12}\right) / 2$ in the conventional two-index notation (Nye 1985). The elastic stiffness matrix in Voigt notation can be written as:

$c_{i j}=\left(\begin{array}{llllll}c_{11} & c_{12} & c_{13} & & & \\ c_{12} & c_{11} & c_{13} & & & \\ c_{13} & c_{13} & c_{33} & & & \\ & & & c_{44} & & \\ & & & & c_{44} & \\ & & & & & c_{66}\end{array}\right)$

These five components of the stiffness matrix for TI material can be derived from five velocity measurements (e.g. Wang 2002), which are referenced concerning the bedding plane (Thomsen 2012; Mavko et al. 2011). When the symmetry axis of isotropy is perpendicular to the bedding planes (assuming here horizontal layering), then the velocities are:

- $V_{P 0}$-bedding-normal (vertical) $P$-velocity,

- $V_{P 90}$-bedding-parallel (horizontal) $P$-velocity,

- $V_{P 45}$-45-to-bedding $P$-velocity,

- $V_{S 0}\left(V_{S H 0}\right)$-bedding-normal (vertical) $S$-velocity polarised horizontally,

- $V_{S 9090}\left(V_{S H 90}\right)$-bedding-parallel (horizontal) $S$-velocity polarised horizontally.

The stiffness coefficients $c_{i j}$ are computed from elastic velocities and the bulk density $\rho$ as follows:

$c_{11}=\rho V_{P 90}^{2}$

$c_{33}=\rho V_{P 0}^{2}$

$c_{44}=\rho V_{S 0}^{2}$

$c_{66}=\rho V_{S 9090}^{2}$

$c_{13}=-c_{44}+\left[4 \rho^{2} V_{P 45}^{2}\left(c_{11}+c_{33}+2 c_{44}\right)+\left(c_{11}+c_{44}\right)\left(c_{33}+c_{44}\right)\right]^{1 / 2}$

Thomsen (1986) introduced three anisotropy parameters $\varepsilon$, $\gamma$, and $\delta$ that have become conventional and common in geophysical applications:

$\varepsilon=\frac{c_{11}-c_{33}}{2 c_{33}}$

$\gamma=\frac{c_{66}-c_{44}}{2 c_{44}}$ $\delta=\frac{\left(c_{13}+c_{44}\right)^{2}-\left(c_{33}-c_{44}\right)^{2}}{2 c_{33}\left(c_{33}-c_{44}\right)}$

In case of weak polar anisotropy, i.e. $|\varepsilon|,|\gamma|,|\delta| \ll 1$, these parameters simplify the equations for angular dependence of velocities in TI media. Elastic velocities in terms of Thomsen parameters can be written as:

$V_{P 0}^{2}=\frac{c_{33}}{\rho}$

$V_{S 0}^{2}=\frac{c_{44}}{\rho}$

$V_{P 90}^{2}=V_{P 0}^{2}(1+2 \varepsilon)$

$V_{S 9090}^{2}=V_{S 0}^{2}(1+2 \gamma)$

and

$\lambda_{13}=c_{13}=\rho\left(V_{P 0}^{2}-2 V_{S 0}^{2}+V_{P 0}^{2} \delta\right)$

where $\lambda_{13}$ is the anisotropic Lame parameter. Thus, the five independent parameters that describe polar anisotropy may be taken as: $V_{P 0}, V_{S 0}, \varepsilon, \gamma$, and $\delta$. Thomsen parameters determine the shape of $\mathrm{P}$ - and S-wavefronts in the TI media. For weak polar anisotropy, the $\varepsilon$ parameter is characterised by the fractional difference between the horizontal and vertical $P$-wave velocity, while the $\gamma$ parameter is the fractional difference between the velocities of $\mathrm{S}$-waves polarised horizontally and propagating horizontally and vertically (Mavko et al. 2011). Therefore, $\varepsilon$ and $\gamma$ are usually called as the $\mathrm{P}$ - and $\mathrm{S}$-wave anisotropy parameters, respectively. The $\delta$ parameter is a more complicate combination of elastic stiffnesses.

Sonic $\operatorname{logs}$ measure only vertical velocities $V_{P 0}$ and $V_{S 0}$. Assuming horizontal bedding of geological formation and vertical wells, they are bedding-normal velocities. Acoustic logs cannot measure Thomsen parameters. However, Li (2006) proposes a method that allows computing $\varepsilon$ and $\delta$ directly from sonic $\operatorname{logs}$ and clay volume $V_{c l}$. Based on laboratory data published by Thomsen (1986), Vernik and Nur (1992), Johnston and Christensen (1995), and Vernik and Liu (1997), Li derives empirical relations between $\varepsilon$ and $\gamma$, bedding-normal velocities of $P$ - and $S$-waves, and clay volume. On the cross-plots $\varepsilon$ versus $V_{P 0}$, and $\gamma$ versus $V_{S 0}$, Li marks three main points: (1) "critical porosity sand point", (2) "zero porosity sand point (or quartz point)", and (3) "zero porosity clay point (or clay mineral point)". The critical porosity sand point (for porosity $\approx 40 \%$ ) indicates suspension domain, i.e. effective shear modulus and $S$-wave velocity are equal to zero. The effective $P$-wave velocity may be approximated by the velocity of brine $\left(V_{P \text { water }}\right)$. The velocities of quartz point approximate the sandstone with zero porosity. These two points are associated with 
zero anisotropy. The clay mineral point is determined with the use of the mean of the data points (from the aforementioned laboratory data) with the largest anisotropic values. Li (2006) computes Thomsen parameters as follows:

$$
\begin{aligned}
& \varepsilon=\frac{\varepsilon_{\text {clay }} \cdot V_{\mathrm{cl}} \cdot\left(V_{\mathrm{P} 0}-V_{P \text { water }}\right)}{V_{P \text { quartz }}-V_{P \text { water }}-\left(V_{P \text { quartz }}-V_{P \text { clay }}\right) \cdot V_{\mathrm{cl}}} \\
& \gamma=\frac{\gamma_{\text {clay }} \cdot V_{\mathrm{cl}} \cdot V_{S 0}}{V_{S \text { quartz }}-\left(V_{S \text { quartz }}-V_{S \text { clay }}\right) \cdot V_{\mathrm{cl}}}
\end{aligned}
$$

where $\varepsilon_{\text {clay }}, \gamma_{\text {clay }}$-Thomsen parameters of clay mineral point, $V_{\mathrm{cl}}$-clay volume, $V_{P 0}, V_{S 0}$-bedding-normal $P$ - and $S$-wave velocities, $V_{P \text { water }}$-an approximation of $P$-wave velocity at critical porosity, $V_{P \text { quartz }}, V_{S \text { quartz }}-P$ - and $S$-wave velocities of quartz, $V_{P \text { clay }}, V_{S \text { clay }}-P$ - and $S$-wave velocities of clay.

$\mathrm{Li}$ (2006) derives the values of anisotropic parameters for clay mineral point from the analysed laboratory data and proposes values: $\varepsilon_{\text {clay }}=0.6$ and $\gamma_{\text {clay }}=0.67$.

Bała et al. (2019) applied this methodology to the shale formation in the Baltic Basin and suggested a technique that allows estimation of $\varepsilon_{\text {clay }}$ and $\gamma_{\text {clay }}$ from the well logging data. They assume that the value of Thomsen parameters in the series of limestones should be low and choose $\varepsilon_{\text {clay }}$ and $\gamma_{\text {clay }}$ so that this condition is met. For $\varepsilon_{\text {clay }}=0.35$ and $\gamma_{\text {clay }}=0.37$, the average values of Thomsen parameters in the series of limestones with $V_{\text {LIM }}>0.65$ are $\varepsilon_{\text {av }}=0.080$ and $\gamma_{\mathrm{av}}=0.069$. Bała et al. (2019) called Thomsen parameters computed with the Li method as "pseudo-anisotropy parameters" because this method does not take into account fractures and micro-fissures.

This method was applied to the lower Paleozoic shale formations in $\mathrm{W} 1, \mathrm{~W} 2$, and $\mathrm{W} 3$ wells to estimate pseudo-anisotropy Thomsen parameters $\varepsilon$ and $\gamma$. Because the wells are vertical and the drilled formations lie almost horizontally, thus, polar anisotropy can be assumed and bedding-parallel velocities of $P$-wave, $V_{P 90}$, and $S$-waves, $V_{S 9090}$, can be computed in the next step with the use of Eqs. $4 \mathrm{e}, 4 \mathrm{~d}$. Velocities recorded by the cross-dipole sonic tool, i.e. $V p$ and $V s$, are considered here as bedding-normal: $V_{P 0}$ and $V_{S 0}$. It should be also mentioned that the cross-dipole sonic tool measures shear velocity in two orthogonal directions $X$ and $Y: V_{s x}$ and $V_{s y}$, respectively. In this study, only $V_{s x}$ is used due to the low quality of the sonic full waveforms recorded in the $Y$-direction. $V_{s x}$ is constantly described here as $V s$.

The three main points on the cross-plots $\varepsilon$ versus $V_{P 0}$ and $\gamma$ versus $V_{S 0}$ were fixed with the following values (Bała et al. 2019): (1) the critical porosity sand point$V_{P \text { water }}=1540 \mathrm{~m} / \mathrm{s}, V_{S \text { water }}=0 \mathrm{~m} / \mathrm{s}, \varepsilon=0$, and $\gamma=0$; (2) the quartz point $-V_{P \text { quartz }}=5980 \mathrm{~m} / \mathrm{s}, V_{S \text { quartz }}=4030 \mathrm{~m} / \mathrm{s}, \varepsilon=0$, and $\gamma=0$; and (3) the clay mineral point $-V_{P \text { clay }}=3500 \mathrm{~m} / \mathrm{s}$, $V_{S \text { clay }}=1780 \mathrm{~m} / \mathrm{s}, \varepsilon_{\text {clay }}$, and $\gamma_{\text {clay }}$ were determined separately in each well. Anisotropy parameters of the clay mineral point were established in reference with very low anisotropy in Kopalino Formation. It was assumed that in this series, for limestones with the carbonate minerals (i.e. calcite + dolomite) volume $>65 \%$, the maximum values of $\varepsilon$ and $\gamma$ should not exceed 0.1 . This assumption provided values: $\varepsilon_{\text {clay }}=0.35$ and $\gamma_{\text {clay }}=0.42$ in well W1, $\varepsilon_{\text {clay }}=0.3$ and $\gamma_{\text {clay }}=0.37$ in well $\mathrm{W} 2$, and $\varepsilon_{\text {clay }}=0.34$ and $\gamma_{\text {clay }}=0.38$ in well W3. These values are much lower than proposed by $\mathrm{Li}$ (2006) but consistent with the results obtained by Bała et al. (2019). Having $\varepsilon_{\text {clay }}$ and $\gamma_{\text {clay }}$, it was possible to compute pseudo-anisotropy parameters in shale formations (Eqs. 5a, b). Results for well $\mathrm{W} 1$ are presented on the cross-plots $\varepsilon$ $-V_{P 0}$, and $\gamma-V_{S 0}$ (Fig. 3). Figure 4a shows average values of pseudo-anisotropy parameters obtained in individual lithological unit derived for all wells. It can be seen that $\gamma$ (a)

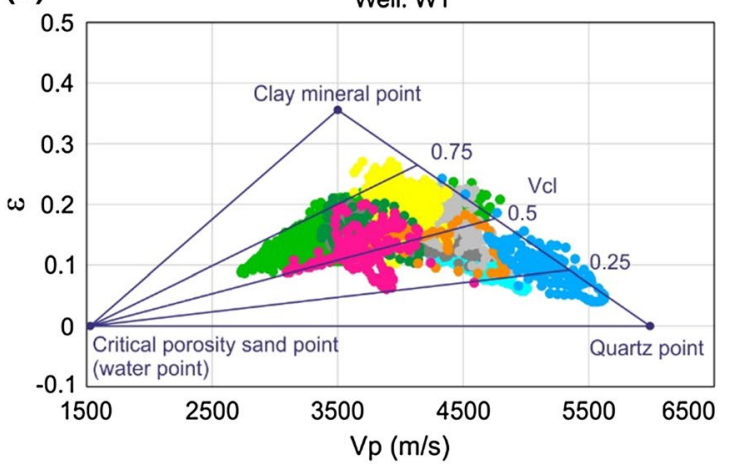

(b)
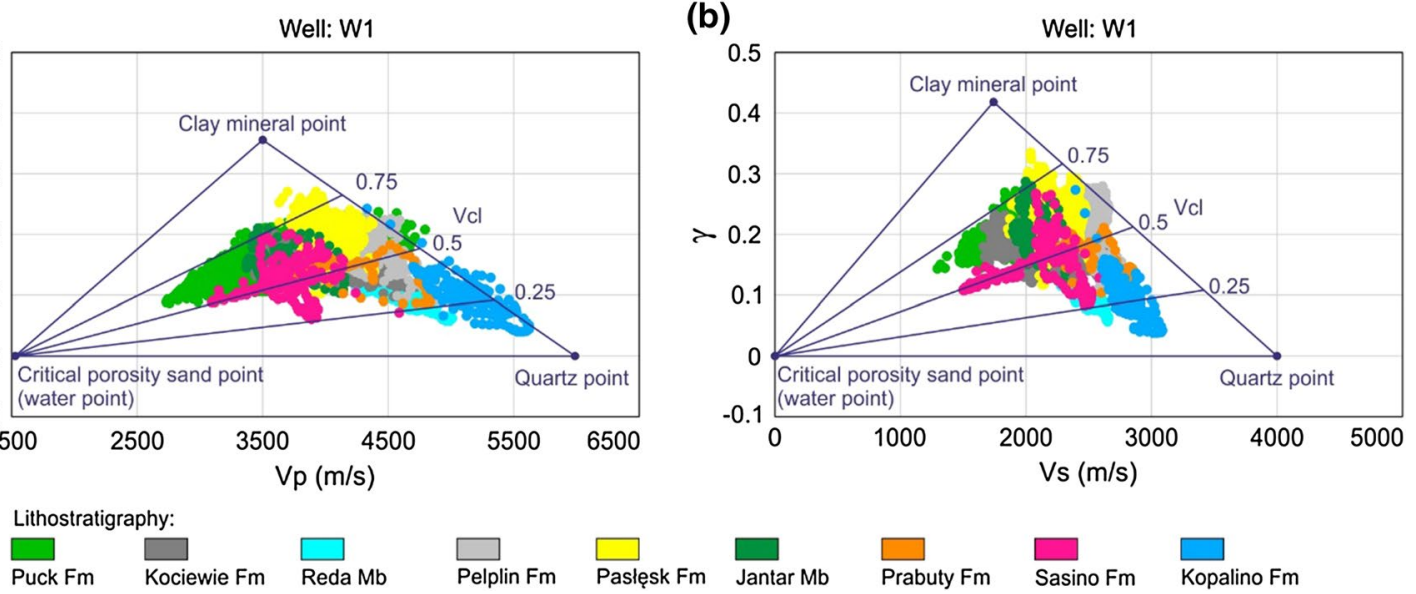

Fig. 3 Relationship between pseudo-anisotropy parameters $\varepsilon$ and $\gamma, P$ - and $S$-wave velocities ( $V p$ and $V s$ ), and clay volume $V_{\text {cl }}$ computed for lower Paleozoic formations in well W1 

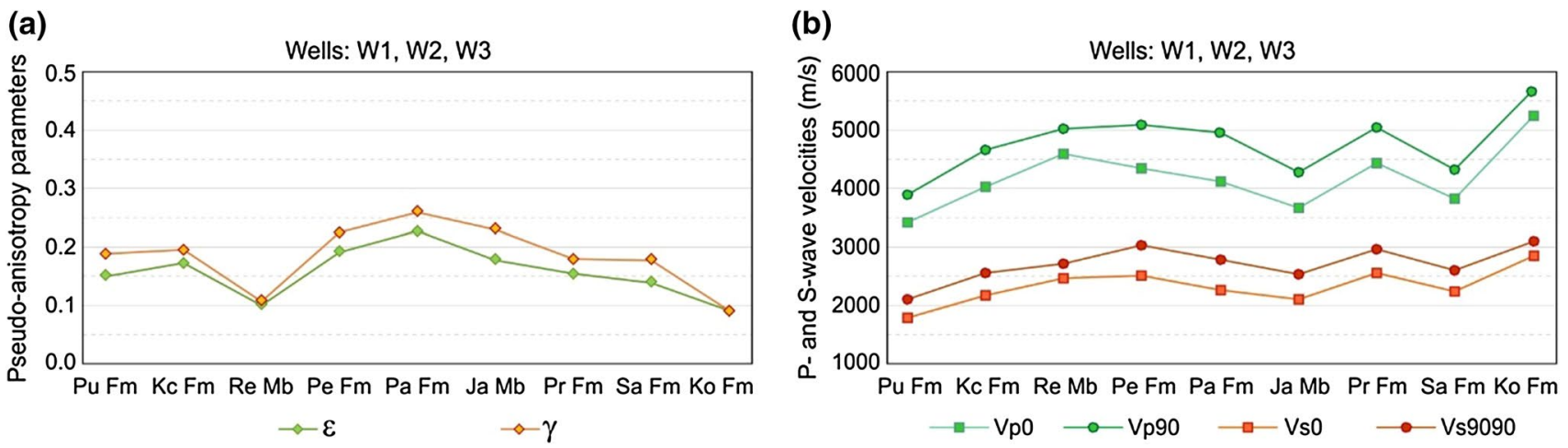

Fig. 4 Average values of a pseudo-anisotropy parameters and $\mathbf{b}$ bedding-normal $\left(V_{P 0}, V_{S 0}\right)$ and bedding-parallel $\left(V_{P 90}, V_{S 9090}\right)$ velocities of $P$ and $S$-wave velocities computed for lower Paleozoic formations in wells W1, W2, and W3

has slightly higher values than $\varepsilon$. Calcareous formations ( $R e$ $\mathrm{Mb}$ and $\mathrm{Ko}$ Fm) have the lowest values of anisotropy, below 0.1 . Claystones and mudstones are characterised by higher values of these parameters, up to 0.2 . The highest parameters, exceeding 0.2, are observed only in Prabuty Formation.

In the next step, bedding-parallel velocities $V_{P 90}$ and $V_{S 9090}$ were computed with the use of Eqs. 4d, 4e. Velocities from cross-dipole sonic log, i.e. $V p$ and $V s$, and pseudo-anisotropy parameters $\varepsilon$ and $\gamma$ obtained from Li (2006) method were applied in the computations. Figure $4 \mathrm{~b}$ compares average values of bedding-normal and bedding-parallel velocities in each individual lithological unit. These values, together with values of pseudo-anisotropy parameters, are summarised in Table 2.

Values of pseudo-anisotropy parameters presented here are associated with the clay volume and thus are related to the intrinsic anisotropy caused by the partial alignment of clay minerals and micro-layering in shales. When the shale layers are horizontal (which is the case for the discussed formations), such medium is polar anisotropic or TIVtransversely isotropic with a vertical axis of symmetry. The TIV anisotropy parameters in Fig. 4a and Table 2 are in accordance with the results of the Backus-averaged well log method applied by Gajek et al. (2018), who obtained epsilon and gamma equal to 0.14 (14\%). The anisotropy of the lower Paleozoic shale formations from the Baltic Basin was also estimated by Stadtmüller et al. (2018). There can be found information that the anisotropy is very weak. It mainly ranges between 1 and 5\%; the dominant anisotropy is $0.4-2 \%$, rarely exceeding $3 \%$ in thin intervals. Higher values of anisotropy, up to 9\%, are observed only in Sasino Formation, but these zones coincide with the low quality of full waveforms recorded by the dipole sonic tool. (These zones were excluded from the analyses presented in this paper.) The discrepancy between the parameters that quantify the anisotropy lies obviously in different methodologies, but the reason is more fundamental. Anisotropy computed by Stadtmüller et al. (2018) is azimuthal, not polar. It is derived from the cross-dipole array waveforms measurements based on shear wave splitting (or shear wave birefringence). This phenomenon appears in TIH medium-transversely isotropic with a horizontal axis of symmetry, where shear waves split into two waves with orthogonal polarizations. One component is polarised along the formation's stiff (or fast) direction, and the other is polarised along the formation's compliant (slow) direction (e.g. Brie et al. 1998). General Alford
Table 2 Average values of measured normal-bedding velocities, $V_{P 0}, V_{S 0}$, computed bedding-parallel velocities, $V_{P 90}, V_{S 9090}$, and pseudoanisotropy parameters, $\varepsilon$ and $\gamma$

\begin{tabular}{lllllll}
\hline Litho-stratigraphy & \multicolumn{6}{l}{ Wells: W1-W2-W3 } \\
\cline { 2 - 7 } & $V_{P 0}(\mathrm{~m} / \mathrm{s})$ & $V_{P 90}(\mathrm{~m} / \mathrm{s})$ & $V_{S 0}(\mathrm{~m} / \mathrm{s})$ & $V_{S 9090}(\mathrm{~m} / \mathrm{s})$ & $\varepsilon$ & $\gamma$ \\
\hline Pu Fm & 3385 & 3860 & 1769 & 2076 & 0.15 & 0.19 \\
Kc Fm & 4002 & 4641 & 2138 & 2521 & 0.17 & 0.20 \\
Re Mb & 4555 & 4989 & 2451 & 2698 & 0.10 & 0.11 \\
Pe Fm & 4306 & 5064 & 2488 & 2995 & 0.19 & 0.23 \\
Pa Fm & 4079 & 4919 & 2239 & 2760 & 0.23 & 0.26 \\
Ja Mb & 3638 & 4235 & 2081 & 2514 & 0.18 & 0.23 \\
Pr Fm & 4398 & 5024 & 2533 & 2947 & 0.15 & 0.18 \\
Sa Fm & 3790 & 4285 & 2218 & 2579 & 0.14 & 0.18 \\
Ko Fm & 5220 & 5671 & 2819 & 3061 & 0.09 & 0.09 \\
\hline
\end{tabular}


rotation (Alford 1986) of sonic waveforms provides the velocity of slow and fast shear wave components. It should be emphasised here that vertical wells provide the best conditions for azimuthal shear anisotropy measurement. TIH anisotropy is caused by oriented inclusions such as vertical fractures and microcracks, or by differences in horizontal stresses. Cross-dipole sonic measurements in vertical wells are insensitive to polar anisotropy, i.e. to effective anisotropy of horizontal layering (Esmersoy et al. 1994). Thus, $\varepsilon$ and $\gamma$ parameters obtained from $\mathrm{Li}$ (2006) method, and computed horizontal $P$ - and $S$-velocities, $V_{P 90}$ and $V_{S 9090}$ respectively, should be treated only as an approximation of the anisotropy in shales, since they consider only TIV anisotropy.

\section{RPT modelling for shale formations}

\section{Lithology discrimination}

The results of the formation evaluation, which were available for each investigated borehole, included volumes of mineral components derived from geochemical logging, total porosity, and water saturation. The sum of all matrix components and total porosity gives 1 (i.e. $100 \%$ of the rock).
It was assumed that the lithology model of the matrix for Silurian and Ordovician shales included: quartz with addition of feldspar and plagioclase $\left(V_{\text {SAN }}\right)$; calcite and dolomite with addition of other carbonate minerals ( $V_{\mathrm{LIM}}$ and $V_{\mathrm{DOL}}$, respectively); sum of clay minerals: illite, illite/smectite, and chlorite $\left(V_{\mathrm{CL}_{\mathrm{C}} \mathrm{dry}}\right)$; pyrite and other sulphur compounds $\left(V_{\mathrm{PYR}}\right)$; and kerogen (organic matter) $\left(V_{\mathrm{KER}}\right)$.

Based on the volume fractions of each mineral, it was possible to make lithology discrimination. The Silurian and Ordovician formations were grouped into three groups: (1) shales, (2) shales with increased organic matter (OM) and saturated with hydrocarbons (HC), and (3) carbonates and marls. The group (2) was determined when $V_{\mathrm{KER}}>2 \%$, $\mathrm{Sw}<45 \%$, and $V_{\mathrm{GAS}}>2 \%$, where $V_{\mathrm{GAS}}$ is a volume fraction of gas, and $S_{\mathrm{w}}$ is the water saturation. When the sum of carbonate minerals exceeded $20 \%$, i.e. $\left(V_{\mathrm{LIM}}+V_{\mathrm{DOL}}\right)>20 \%$, the formations were classified as the group (3). The remaining deposits were considered as the group (1). Results of the lithology discrimination are presented in Fig. 5 and are included in Tables 3 and 5. The matrix average mineral composition of each lithology group was used for following effective bulk and shear moduli, as well as $P$-wave modulus computation, and creating the rock physics templates with
Fig. 5 Matrix average mineral composition of shales (1), shales enriched in organic matter and saturated with hydrocarbons (2), and carbonates, marly, and calcareous deposits (3); $V_{\mathrm{SAN}}, V_{\mathrm{LIM}}, V_{\mathrm{DOL}}, V_{\mathrm{CL}_{-} \mathrm{dry}}$, $V_{\mathrm{PYR}}, V_{\mathrm{KER}}$-volume fractions of quartz with addition of other minerals, limestone, dolomite, sum of dry clay, pyrite, and kerogen, respectively
(1) Shales

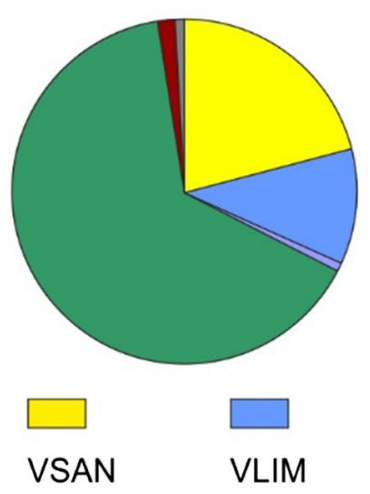

(2) Shales with organic matter and hydrocarbons

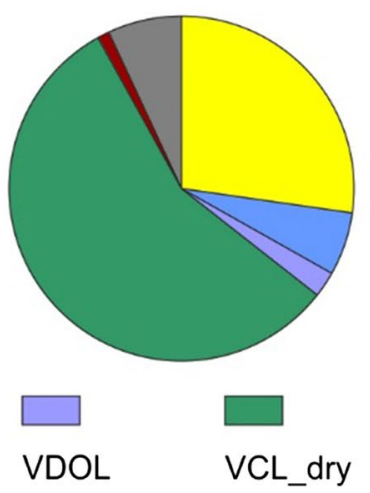

(3) Carbonates and marls
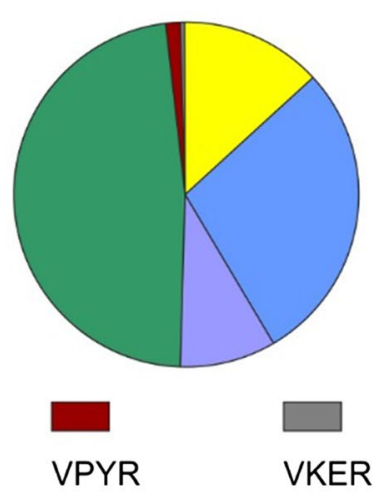

Table 3 Average mineral composition of matrix derived from lithological discrimination and parameters used for calculating effective elastic moduli of multi-mineral rockframes: GEM model. Sources of $K, G$, and $\rho$ : 1 - Carmichael (1989); 2-Mavko et al. (2011); 3-Bała (2015); 4-Stadtmüller et al. (2018)

\begin{tabular}{|c|c|c|c|c|c|c|c|}
\hline \multirow[t]{2}{*}{ Mineral } & \multicolumn{3}{|c|}{$\begin{array}{l}\text { Average mineral volume fractions in } \\
\text { matrix (W1-W2-W3 wells) }\end{array}$} & \multirow[t]{2}{*}{$K(\mathrm{GPa})$} & \multirow[t]{2}{*}{$G(\mathrm{GPa})$} & \multirow[t]{2}{*}{$\rho \times 10^{3}\left(\mathrm{~kg} / \mathrm{m}^{3}\right)$} & \multirow{2}{*}{$\begin{array}{l}\text { Sources } \\
\text { of } K, \\
G, \rho\end{array}$} \\
\hline & (1) Shales & $\begin{array}{l}\text { (2) Shales } \\
\text { with OM and } \\
\text { HC }\end{array}$ & $\begin{array}{l}\text { (3) Carbon- } \\
\text { ates and } \\
\text { marls }\end{array}$ & & & & \\
\hline Quartz & 0.211 & 0.274 & 0.130 & 34 & 44 & 2.65 & $2 ; 4$ \\
\hline Calcite & 0.107 & 0.058 & 0.286 & 72 & 30 & 2.71 & $2 ; 4$ \\
\hline Dolomite & 0.008 & 0.025 & 0.088 & 76 & 49 & 2.87 & $2 ; 4$ \\
\hline Sum of clays & 0.648 & 0.563 & 0.477 & 39 & 25 & 2.70 & $3 ; 4$ \\
\hline Pyrite & 0.017 & 0.009 & 0.012 & 147 & 132 & 4.93 & 1 \\
\hline Kerogen & 0.009 & 0.070 & 0.007 & 5.53 & 3.20 & 1.25 & $3 ; 4$ \\
\hline
\end{tabular}


the use of the GEM theory and the SM equations. The workflows are described in detail in the next chapters.

The lithology discrimination exposed differences between shales and organic shales and allowed distinguishing them from carbonates and marly deposits. The principal component of each lithology group is clay minerals, comprising $65 \%$ of the matrix in shales, $56 \%$ in organic shales, and $47 \%$ in calcareous formations. Organic shales have significantly higher kerogen and quartz volumes in comparison with shales, but lower carbonate minerals content. Marly shales, marls, and carbonates are characterised by a higher amount of carbonate minerals, reduced volume of quartz, and the lowest kerogen volume. Pyrite content in each lithology group is approximately similar; however, in shales enriched in organic matter, its volume is the lowest.

For rock physics modelling, the $V p / V s$ ratio $(V p V s)$ versus acoustic impedance (AI) cross-plot was created. In each well, the full waveform sonic logs were recorded, and $V p$ and $V s$ data were available. Thus, it was possible to obtain reliable $V p / V s$ ratio that is a lithology discriminator as well as a very good gas indicator. Using $V p$ and bulk density logs, the values of AI were computed. Density measurement might be of great interest in case of organic shale because the low-density kerogen may significantly lower the overall rock bulk density. Figure 6 shows the $V p V s$ versus AI crossplot comprising all the data, i.e. from the Silurian Puck Formation (the youngest and the shallowest) to the Ordovician Kopalino Formation (the oldest and the deepest), recorded in three investigated wells. The upper part of the figure presents lithostratigraphic division, while the lower part displays the results of lithology discrimination.

When analysing the cross-plot with lithostratigraphic division, it can be seen a clear compaction trend-the deeper the shale formation is, the higher the acoustic impedance and the lower the $V p / V s$ ratio it has. The exceptions are the Jantar Member and the Sasino Formation, which have significantly lower $V p / V s$ ratio and reduced acoustic impedance values. The compaction trend is not also followed by the calcareous mudstones of Reda Member, limestones of Kopalino Formation, and the marly deposits of Prabuty Formation shales. These formations have higher acoustic impedance than the shales and increased $V p / V s$ ratio.

To explain these features, average values of bulk density, RHOB av, compressional and shear velocities, $V p$ av and $V s$ av, and kerogen volume, $V_{\mathrm{KER}}$ av, have been calculated in each lithological unit and for W1, W2, and W3 wells together. The results are presented in Fig. 7.

The average values of the bulk density and the $P$ - and $S$-velocities put together with the kerogen volume reveal that the higher organic matter content in the Jantar $\mathrm{Mb}$ and Sasino Fm shales significantly reduces the compressional wave velocity and the bulk density. The effect of increased kerogen volume on the shear velocity is weaker. In this case, both $V p / V s$ ratio and AI decrease. As a result, the Jantar Member and the Sasino Formation points on the $V p V s$ versus AI cross-plot are shifted from the compaction trend towards the lower values of $V p / V s$ ratio and acoustic impedance and it is possible to mark the kerogen trend on the plot.

Increased $V p$ values can explain the opposite shift trend of calcareous sediments. In this case, the bulk density has less impact on the acoustic impedance: the average bulk density of the shales is very high, ca. $2.65-2.69 \times 10^{3} \mathrm{~kg} / \mathrm{m}^{3}$ due to significant compaction caused by the great depths, while the average bulk density of the Kopalino limestone is $2.71 \times 10^{3} \mathrm{~kg} / \mathrm{m}^{3}$. Additionally, carbonates have higher $V p / V s$ ratio than quartz-based siliciclastic rock because $V p$ increases faster than $V s$ with growing carbonate content (Schön 1996). These resulted in shifting the points towards higher $V p / V s$ ratio and acoustic impedance.

The $V p V s-\mathrm{AI}$ cross-plot with superimposed lithology discrimination results confirms preliminary conclusions. The organic shales are shifted towards lower $V p / V s$ ratio and lower acoustic impedance values, while limestones, marls, and calcareous deposits are placed in the region of higher $V p / V s$ ratio and acoustic impedance values.

\section{Elastic bounds}

The simplest bounds of elastic moduli are the Voigt (1910) and Reuss (1929) bounds. No matter how the complex the composite is, its elastic moduli are constrained by these bounds.

The Voigt bound (upper limit) is also called the isostrain average. It assumes that all components of a multi-phase medium experience the same strain. The Voigt bound gives maximum possible moduli of the composite - a mixture of the constituents cannot be elastically stiffer than the arithmetic average of the components moduli:

$M_{\mathrm{V}}=\sum_{i=1}^{N} f_{i} \cdot M_{i}$

where $f_{i}$ is the volume fraction of the $i$ th component of the material, and $M_{i}$ is the elastic modulus of the $i$ th component of the material.

The Reuss bound (lower limit) assumes constant stress field throughout the material. It describes an isostress situation that applies to suspension of solid grains in a fluid and fluid mixing. The Reuss lower bound gives the minimum possible elastic moduli for a given material. A mixture of the components of the material cannot be elastically softer than the harmonic average of the components moduli:

$$
\frac{1}{M_{\mathrm{R}}}=\sum_{i=1}^{N} \frac{f_{i}}{M_{i}}
$$


Fig. 6 Lithostratigraphic division and results of lithology discrimination in wells $\mathrm{W} 1, \mathrm{~W} 2$ and W3; compaction, carbonates, and kerogen trends are superimposed on the plot

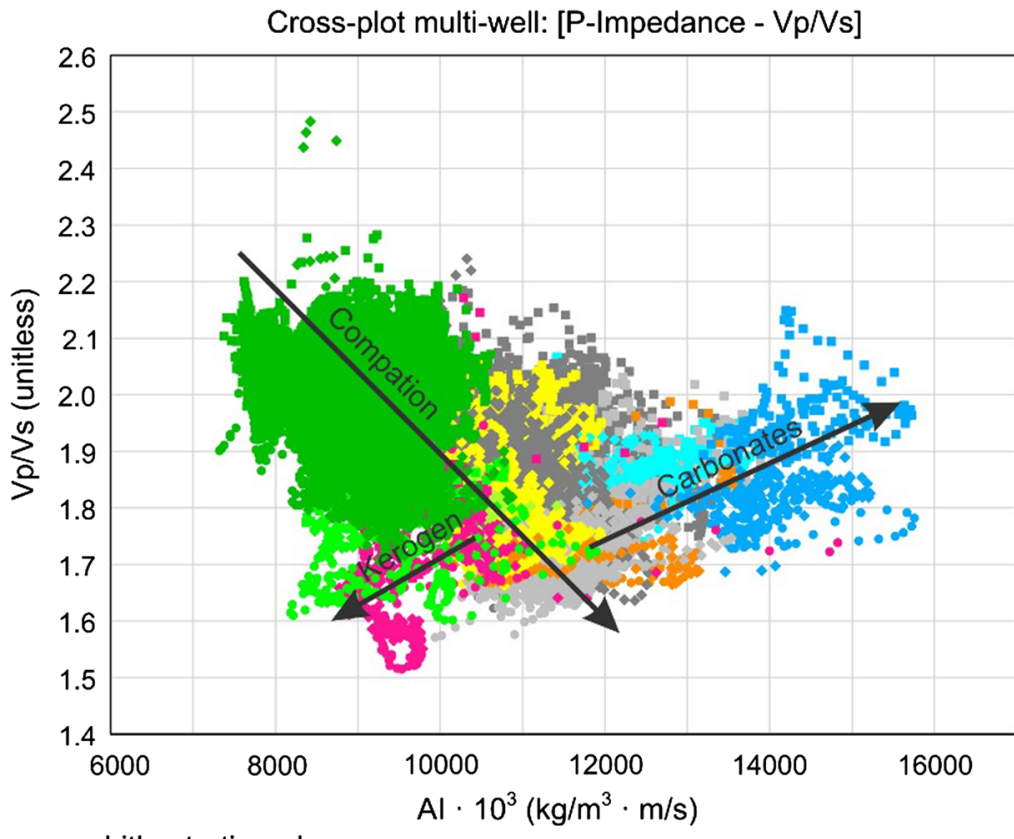

Wells:

$\diamond W 1$

$\square$ W2

O W3
Lithostratigraphy:
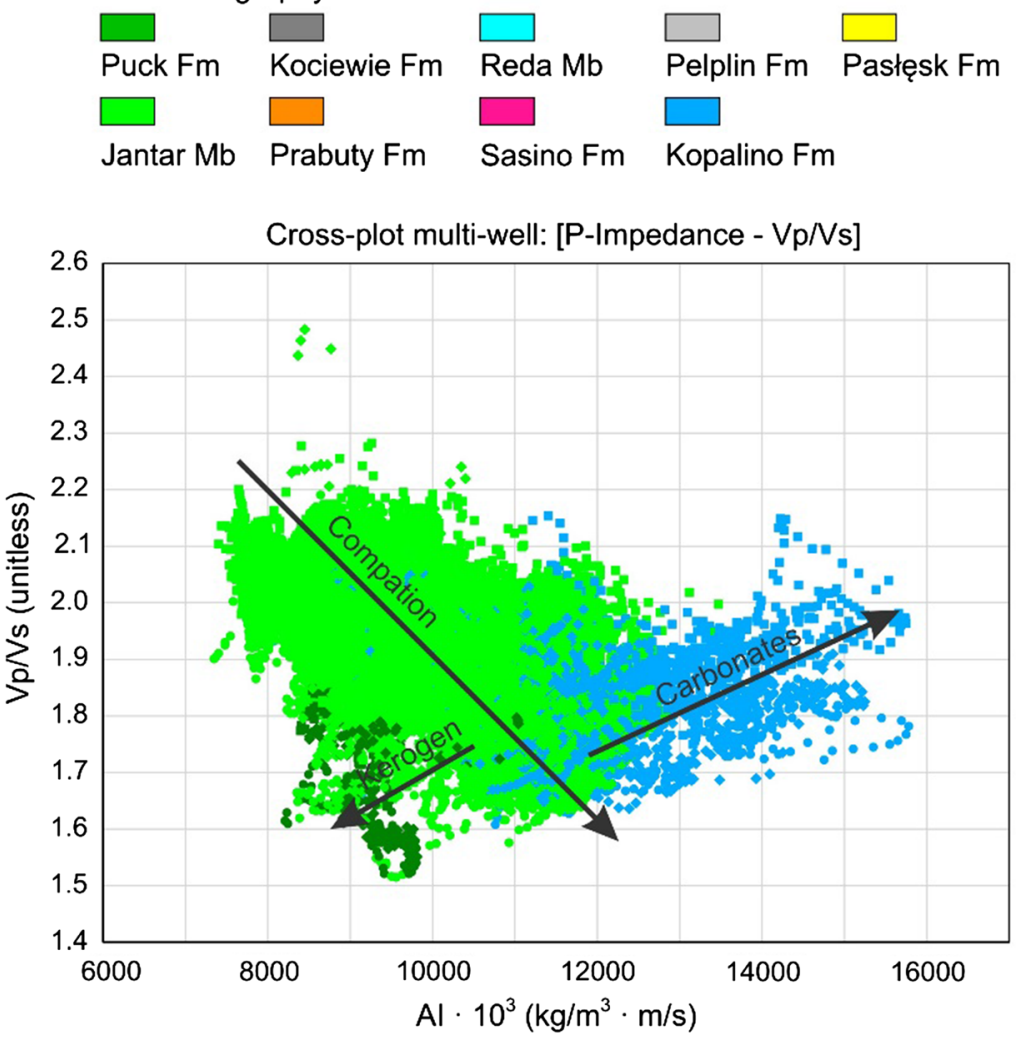

Wells:

$\diamond W_{1}$

$\square$ W2

O W3

Lithology discrimination groups:

(1) Shales
(2) Shales with organic matter and hydrocarbons
(3) Carbonates and marls
The $M$ in the Voigt and Reuss averages can represent any elastic modulus. Usually, the Voigt and the Reuss bounds of the bulk modulus $M=K$ and the shear modulus $M=G$ are calculated, and then, the other moduli are computed using the rules of isotropic linear elasticity.

When we need only to know the estimation of the moduli (instead of the range of the allowable values), the average of 
Fig. 7 Average values of bulk density (RHOB av), compressional and shear velocities ( $V p$ av and $V s$ av), and kerogen volume (VKER av) in each lithological unit from three investigated wells

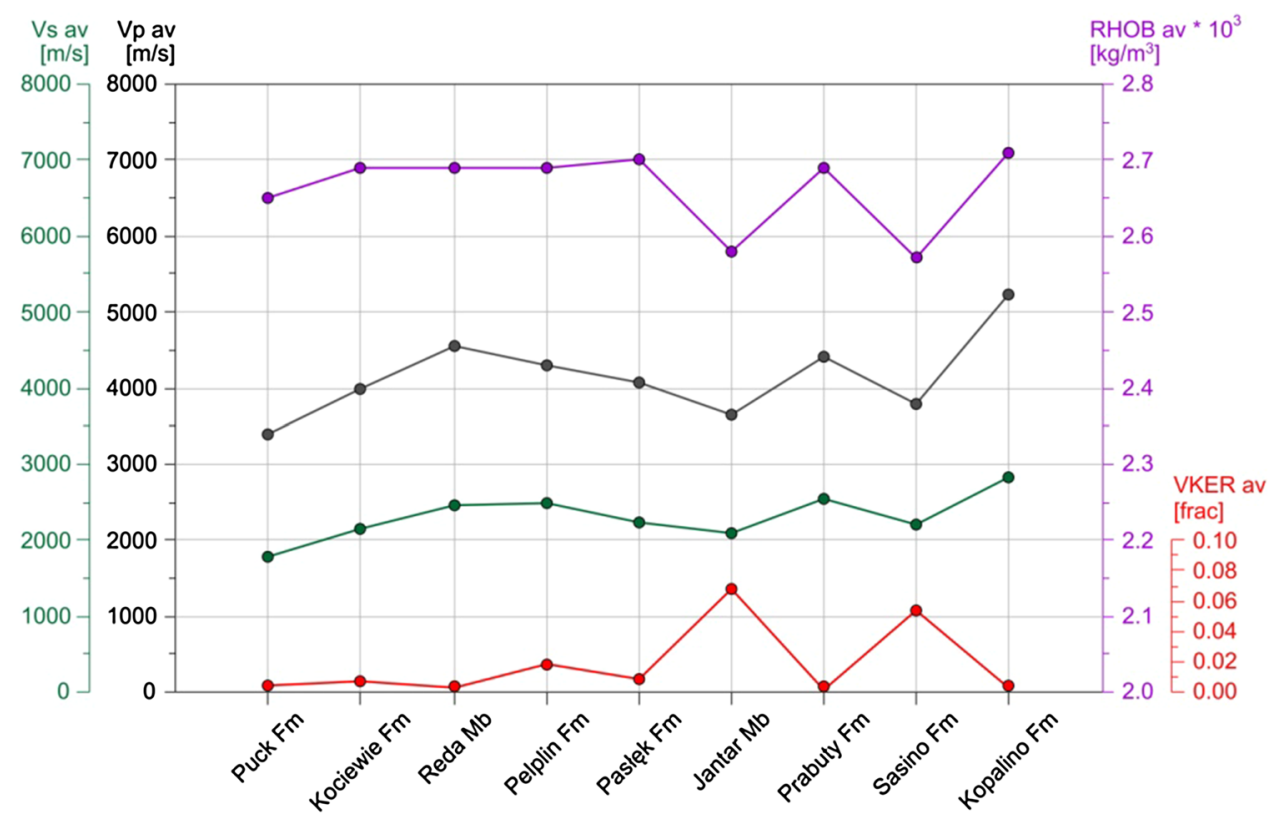

the Voigt and Reuss bounds is calculated, which is referred as the Voigt-Reuss-Hill, or the Hill average:

$M_{\mathrm{H}}=\frac{M_{\mathrm{V}}+M_{\mathrm{R}}}{2}$

The Hill average is relatively accurate when all components of the composite have similar elastic moduli. It is also commonly used to estimate the modulus of the multi-mineral rock matrix.

The narrowest possible range of the elastic moduli of the mixture of the two or more components, without specifying anything about their geometrical arrangement, is given by the Hashin-Shtrikman-Walpole bounds (or in case of two components by the Hashin-Shtrikman bounds). For an isotropic material composed of more than two phases, the upper and lower Hashin-Shtrikman-Walpole bounds are written as (Berryman 1995):

$$
\begin{aligned}
K^{\mathrm{HS} \pm} & =\left[\sum_{i=1}^{N} \frac{f_{i}}{K_{i}+\frac{4}{3} G_{\mathrm{m}}}\right]^{-1}-\frac{4}{3} G_{\mathrm{m}} \\
G^{\mathrm{HS} \pm} & =\left[\sum_{i=1}^{N} \frac{f_{i}}{G_{i}+\zeta_{\mathrm{m}}}\right]^{-1}-\zeta_{\mathrm{m}}
\end{aligned}
$$

where $\zeta_{m}$ is defined as:

$\zeta_{\mathrm{m}}\left(K_{\mathrm{m}}, G_{\mathrm{m}}\right)=\frac{G_{\mathrm{m}}}{6}\left(\frac{9 K_{\mathrm{m}}+8 G_{\mathrm{m}}}{K_{\mathrm{m}}+2 G_{\mathrm{m}}}\right)$

$f_{i}$ is the volume fraction of the $i$ th component of the material, $M_{i}, G_{i}$ are the bulk and shear moduli of the $i$ th component of the material, and $M_{\mathrm{m}}, G_{\mathrm{m}}$ are the maximum (minimum) moduli of the components.

The upper (lower) bound is computed when $K_{\mathrm{m}}, G_{\mathrm{m}}$, and $\zeta_{\mathrm{m}}\left(K_{\mathrm{m}}, G_{\mathrm{m}}\right)$ are the maximum (minimum) moduli of the constituents of the material. Usually one component of the material has both the maximum bulk and shear moduli; however, they can come from different components, for example, a mixture of calcite $(K=72 \mathrm{GPa}, G=30 \mathrm{GPa})$ and quartz $(K=34 \mathrm{GPa}, G=44 \mathrm{GPa})$.

\section{Rock physics template-granular effective medium model}

Firstly, to create a rock physics template with the use of the GEM theory, the moduli of dry rock are needed for two porosity end-members: the moduli of the dry rock at zero porosity (i.e. the moduli of the solid multi-mineral matrix) and the dry moduli of the rock at the high (i.e. critical) porosity $\phi_{\mathrm{c}}$. The critical porosity (Nur 1992) is a structure-dependent porosity at which the framework stiffness goes to zero. It means that any porous material ceases to exist above a certain porosity limit, and rock starts falling apart. For sandstone, critical porosity is $0.36-0.4$ (Mavko et al. 2011). Shales have higher critical porosity, $\phi_{\mathrm{c}} \approx 0.6-0.7$, due to the card-stack arrangements of clay particle and (Avseth et al. 2001). The effective moduli of the solid multi-mineral matrix may be calculated with the use of the Hill average or using the average of more rigorous lower and upper Hashin-Shtrikman-Walpole bounds. The GEM theory assumes that the rock is composed of randomly packed spheres, which is not fully applicable for shales. However, the shales, apart from plate-like clay, consist of other minerals like quartz, feldspars, and carbonates that can 
be modelled with the use of the granular approach. The dry rock elastic moduli for critical porosity can be computed with the use of the Hertz-Mindlin contact theory (Mindlin 1949). $K_{\mathrm{HM}}$ and $G_{\mathrm{HM}}$ are given by:

$K_{\mathrm{HM}}=\left[\frac{n^{2}\left(1-\phi_{\mathrm{c}}\right)^{2} G_{\mathrm{ma}}^{2}}{18 \pi^{2}\left(1-v_{\mathrm{ma}}\right)^{2}} P\right]^{\frac{1}{3}}$

$G_{\mathrm{HM}}=\frac{5-4 v_{\mathrm{ma}}}{5\left(2-v_{\mathrm{ma}}\right)}\left[\frac{3 n^{2}\left(1-\phi_{\mathrm{c}}\right)^{2} G_{\mathrm{ma}}^{2}}{2 \pi^{2}\left(1-v_{\mathrm{ma}}\right)^{2}} P\right]^{\frac{1}{3}}$

$v_{\mathrm{ma}}=\frac{3 K_{\mathrm{ma}}-2 G_{\mathrm{ma}}}{2\left(3 K_{\mathrm{ma}}+G_{\mathrm{ma}}\right)}$

where $K_{\mathrm{ma}}, G_{\mathrm{ma}}$, and $v_{\mathrm{ma}}$ are the effective bulk modulus, the effective shear modulus, and the effective Poisson's ratio of the dry rock multi-mineral skeleton, respectively, $\phi_{\mathrm{c}}$ is a critical porosity, $P$ is the confining pressure acting on the rock, and $n$ is a coordination number.

The coordination number $n$ is a number of contacts per grain (assuming the rock is composed of spherical grains). It may be estimated by relation (Avseth et al. 2001):

$n=17-20 \phi_{\mathrm{c}}$

Hertz-Mindlin contact model is used for precompacted granular rocks when the spheres (grains) are first pressed together, and a tangential force is applied afterwards (Mavko et al. 2011).

Then, the elastic moduli of dry rock between the two endmember porosity points are estimated based on the modified Hashin-Shtrikman bounds. They are computed directly from Eqs. 9a-c if the rock is composed of a matrix with its volume fraction $(1-\phi)$ and porosity $\phi$. In modified Hashin-Shtrikman bounds, the porosity $\phi$ is replaced with $\phi / \phi_{\mathrm{c}}$. We can assume that the diagenesis of rock begins with unconsolidated, highly porous sediment that gradually gets compacted until reaching critical porosity. When the critical porosity is achieved, the cementation is the primary diagenetic process that causes a decrease in porosity and an increase in elastic moduli. The modified Hashin-Shtrikman bounds separate the trends of consolidated and unconsolidated rock elastic moduli. For unconsolidated or soft sediments, when the porosities are higher than the critical porosity, the compaction trend can be modelled with the use of the lower modified Hashin-Shtrikman bound. It allows obtaining the bulk and the shear moduli of dry rock when the cement is deposited away from grain contacts. For a cemented reservoir, it has been found that the cementation trend can be modelled using the modified upper Hashin-Shtrikman bound (Avseth et al. 2010; Mavko et al. 2011).

Next, the Gassmann fluid substitution is performed to estimate the effect of saturation on the dry rock frame. Having computed dry rock bulk and shear moduli at various porosities, the Gassmann's equation allows obtaining their values at various saturations. The shear modulus of saturated rock is independent of fluid content. Re-arranged Gassmann's relation that allows direct computation of the saturated rock moduli $K_{\text {sat }}$ is as follows (Mavko et al. 2011):

$K_{\mathrm{sat}}=K_{\mathrm{dry}}+\frac{\left(1-K_{\mathrm{dry}} / K_{\mathrm{ma}}\right)^{2}}{\phi / K_{\mathrm{fl}}+(1-\phi) / K_{\mathrm{ma}}-K_{\mathrm{dry}} / K_{\mathrm{ma}}^{2}}$

and

$G_{\text {sat }}=G_{\text {dry }}$

where $K_{\text {sat }}$ and $G_{\text {sat }}$ are the bulk and the shear modulus of the saturated rock as a function of porosity and saturation, $K_{\mathrm{dry}}$ and $G_{\mathrm{dry}}$ are the bulk and the shear modulus of the dry rock frame as a function of porosity, $K_{\mathrm{ma}}$ is the bulk modulus of the skeleton (i.e. the effective bulk modulus of the multimineral matrix), and $K_{\mathrm{fl}}$ is the fluid mixture bulk modulus.

$K_{\text {dry }}$ and $G_{\text {dry }}$ can be derived from the modified Hashin-Shtrikman bounds; $K_{\mathrm{ma}}$ (and $G_{\mathrm{ma}}$, which is hidden in $G_{\mathrm{dry}}$ ) may be computed as the average of the upper and lower Hashin-Shtrikman-Walpole bounds or as the Hill average. The pore fluid properties depend on the reservoir pressure, temperature, and water saturation $S_{w}$. The reservoir fluid can be water, gas, oil, or a mixture of them. Assuming homogeneous mixture, one can use the lower Reuss bound for calculation of the bulk modulus of the fluid mixture. For patchy saturation $K_{\mathrm{ff}}$, the Voigt bound should be utilised.

Finally, when the bulk and the shear moduli of saturated rock are calculated as a function of porosity and saturation, $K_{\text {sat }}\left(\phi, S_{\mathrm{w}}\right)$ and $G_{\text {sat }}(\phi)$, one can compute Vp and $V s$ as follows:

$V_{p}\left(\phi, S_{\mathrm{w}}\right)=\sqrt{\frac{K_{\mathrm{sat}}\left(\phi, S_{\mathrm{w}}\right)+\frac{4}{3} G_{\mathrm{sat}}(\phi)}{\varrho_{\mathrm{sat}}\left(\phi, S_{\mathrm{w}}\right)}}$

$V_{s}\left(\phi, S_{\mathrm{w}}\right)=\sqrt{\frac{G_{\mathrm{sat}}(\phi)}{\rho_{\mathrm{sat}}\left(\phi, S_{\mathrm{w}}\right)}}$

$\varrho_{\mathrm{sat}}\left(\phi, S_{\mathrm{w}}\right)=\varrho_{\mathrm{ma}}(1-\phi)+\varrho_{\mathrm{w}} S_{\mathrm{w}} \phi+\varrho_{\mathrm{HC}}\left(1-S_{\mathrm{w}}\right) \phi$

where $\varrho_{\mathrm{sat}}, \varrho_{\mathrm{ma}}, \varrho_{\mathrm{w}}, \varrho_{\mathrm{HC}}$ are the bulk density of saturated rock, and the matrix, water, and hydrocarbon densities, respectively.

These parameters are used for further calculations of $V p / V s$ ratio and acoustic impedance. 


\section{Rock physics template-shale model}

Vernik and Kachanov (2010) proposed a universal semiempirical model that relates bedding-normal velocity and porosity in fully water-saturated conventional shales preconsolidated to porosity values of $40-45 \%$. This model incorporates clay content, $V_{\mathrm{cl}}$, which is the key lithologic variable, and is consistent with the gradual compaction caused by the increase in effective stress:

$V_{P 0}=\sqrt{\frac{c_{33}}{\rho_{\mathrm{b}}}}=\sqrt{\frac{c_{33 \mathrm{~m}}(1-\phi)^{k}}{\rho_{\mathrm{m}}(1-\phi)+\rho_{\mathrm{f}} \phi}}$

where $c_{33 \mathrm{~m}}$ is the bedding-normal elastic stiffness of the anisotropic solid matrix composed of clay and silt (nonclay components), $k$ is the pseudo-shape factor, $\phi$ is the total porosity, and $\rho_{\mathrm{b}}, \rho_{\mathrm{m}}, \rho_{\mathrm{f}}$ are the bulk, matrix, and fluid densities, respectively.

The model assumes bimodal shale composition with aligned (laminated) plate-like clays and nonclay components. Thus, the bedding-normal stiffness of the matrix can be computed by Reuss average:

$c_{33 \mathrm{~m}}=\left(\frac{V_{\text {cl_dry }}}{c_{33 \mathrm{cl}}}+\frac{1-V_{\text {cl_dry }}}{M_{n \mathrm{cl}}}\right)^{-1}$

where $V_{\text {cl_dry }}$ is the volume fraction of the dry clay content in the solid matrix, $c_{33 \mathrm{cl}}$ is the elastic stiffness of clay minerals, and $M_{n c 1}$ is the $P$-wave modulus of the remaining minerals, mostly quartz, feldspars, and carbonates.

The pseudo-shape factor $k$ is a clay content-dependent empirical exponent:

$k=5.3-1.3 \cdot V_{\text {cl_dry }}$

The shale model works best with the shale grain mineral density $\rho_{m}$ that assumes exponential variation caused by compaction and the smectite-to-illite transition:

$\rho_{\mathrm{m}}=2.76+0.001\left\{\left(\rho_{\mathrm{b}}-2\right)-230^{\left[-4\left(\rho_{\mathrm{b}}-2\right)\right]}\right\}$

This grain density model can be applied to shales with the bulk density $\rho_{\mathrm{b}}$ exceeding $1.9-2.0 \times 10^{3} \mathrm{~kg} / \mathrm{m}^{3}$. For shales at porosity below 0.25 , regardless of clay content, the grain density $\rho_{\mathrm{m}}$ may be taken as $2.73 \times 10^{3} \mathrm{~kg} / \mathrm{m}^{3}$.

Shear wave velocity in the shale model is inverted from $V p-V s$ empirical relation:

$V_{S 0}=\left(a \cdot V_{P 0}^{4}+b \cdot V_{P 0}^{2}+c\right)$

where $V_{S 0}$ is the compressional wave velocity given in Eq. 15, $a=0.000284, b=0.287$, and $c=0.79$.

The coefficients in Eq. 18 are calibrated using shales with clay volume from 40 to $70 \%$ and a predominantly illite/smectite/chlorite clay mineralogy. This relation describes an accelerated, nonlinear drop in $V_{\mathrm{S}}$ as the sediment porosity approaches $40 \%$, which is consistent with the dipole shear data in soft shales.

For predominantly illite/chlorite/kaolinite clay mineralogy, Vernik and Kachanov (2010) derived the elastic bedding-normal stiffnesses: $M\left(c_{33 \mathrm{cl}}\right)=33.4 \mathrm{GPa}$ and $G\left(c_{44 \mathrm{cl}}\right)=8.5 \mathrm{GPa}$ from the shale model using the core and $\log$ data. Assuming the Thomsen parameters of these clay aggregates are: $\varepsilon=0.3, \gamma=0.25$, and $\delta=0.5 \cdot \varepsilon=0.15$ (Vernik 2016), one can compute the remaining components of the stiffness matrix for polar anisotropy medium. Then, the bedding-parallel stiffnesses are: $M\left(c_{11 \mathrm{cl}}\right)=53.4 \mathrm{GPa}$ and $G\left(c_{66 \mathrm{cl}}\right)=12.7 \mathrm{GPa}$. The anisotropic Lame parameter is: $\lambda\left(c_{13 \mathrm{cl}}\right)=21.0 \mathrm{GPa}$.

\section{Application of granular effective medium model}

RPT modelling of Silurian and Ordovician deposits with the use of the GEM theory involved five steps and was based on the methodology described above (Mavko et al. 2011; CGG 2015). The workflow was as follows:

1. Computing the initial effective bulk and shear moduli of the multi-mineral matrix, $K_{\mathrm{ma}}$ and $G_{\mathrm{ma}}$, separately for each lithology group, with the use of the Hashin-Shtrikman-Walpole bounds (Eqs. 9a-c).

Densities and elastic moduli of the main mineral components were chosen as presented in Table 3 .

2. Computing the moduli of the dry rock frame for an effective pressure and a critical porosity, $K_{\mathrm{dry}}\left(\phi_{\mathrm{c}}\right)$ and $G_{\mathrm{dry}}\left(\phi_{\mathrm{c}}\right)$, using the contact Hertz-Mindlin theory (Eqs. 10, 11).

Since there was no evidence of overpressure in the shale formations, the effective pressure was calculated using standard gradients for the hydrostatic and overburden pressure. The effective pressure was fixed at $0.039 \mathrm{GPa}$ at a depth of $2900 \mathrm{~m}$, which is the approximate depth of sweet spot formations. Critical porosity for shales and shales with increased organic matter content was set as 0.7 , for carbonates and marls as 0.4. The corresponding coordination numbers (Eq. 11) were equal to 3 and 9.

3. Computing the moduli of the dry rock frame over a range of porosities, $K_{\mathrm{dry}}\left(\phi<\phi_{\mathrm{c}}\right)$ and $G_{\mathrm{dry}}\left(\phi<\phi_{\mathrm{c}}\right)$, using the modified Hashin-Shtrikman bounds. Both bounds, i.e. the lower and the upper, were applied to see how the compaction and the cementation trends would be modelled for the lower Paleozoic shale formations.

4. Performing fluid substitution with the Gassmann's Eqs. (12a, 12b) to calculate saturated rock moduli: $K_{\text {sat }}\left(\phi, S_{\mathrm{w}}\right)$ and $G_{\text {sat }}(\phi)$. It was assumed that the pore space in shales with kerogen is filled with the homo- 
Table 4 Fluid properties used in rock physics modelling. Sources of $K, G$, and $\rho$ : 1 -Bała (2015); 2-CGG (2015); 3-Stadtmüller et al. (2018)

\begin{tabular}{|c|c|c|c|c|c|c|c|}
\hline \multirow[t]{2}{*}{ Fluid type } & \multicolumn{3}{|c|}{ Water/gas/oil saturation (fraction) } & \multirow[t]{2}{*}{$K(\mathrm{GPa})$} & \multirow[t]{2}{*}{$G(\mathrm{GPa})$} & \multirow[t]{2}{*}{$\rho \times 10^{3}\left(\mathrm{~kg} / \mathrm{m}^{3}\right)$} & \multirow{2}{*}{$\begin{array}{l}\text { Sources } \\
\text { of } K, \\
G, \rho\end{array}$} \\
\hline & (1) Shales & $\begin{array}{l}\text { (2) Shales } \\
\text { with OM and } \\
\text { HC }\end{array}$ & $\begin{array}{l}\text { (3) Carbon- } \\
\text { ates and } \\
\text { marls }\end{array}$ & & & & \\
\hline Water & 1 & 0.2 & 1 & 2.6 & 0 & 1.05 & 1 \\
\hline Gas & 0 & 0.74 & 0 & 0.05 & 0 & 0.1 & $1 ; 3$ \\
\hline Oil & 0 & 0.06 & 0 & 1 & 0 & 0.75 & 2 \\
\hline
\end{tabular}

Table 5 Average mineral composition of shale matrix (lithological discrimination, group 1) and parameters used for calculating beddingnormal $P$ - and $S$-wave velocities with the use of the shale model.
Sources of $M, G$, and $\rho$ : 1-Vernik and Kachanov (2010); 2-Mavko et al. (2011); 3-Vernik (2016)

\begin{tabular}{|c|c|c|c|c|c|}
\hline Mineral & $\begin{array}{l}\text { Average mineral volume fractions in } \\
\text { matrix (W1-W2-W3 wells) } \\
\text { (1) Shales }\end{array}$ & $M\left(C_{33}\right)(\mathrm{GPa})$ & $G\left(C_{44}\right)(\mathrm{GPa})$ & $\rho \times 10^{3}\left(\mathrm{~kg} / \mathrm{m}^{3}\right)$ & $\begin{array}{l}\text { Sources of } \\
M, G, \rho\end{array}$ \\
\hline Quartz & 0.211 & 95.6 & 44 & 2.65 & $2 ; 3$ \\
\hline Calcite & 0.107 & 108.9 & 30 & 2.71 & $2 ; 3$ \\
\hline Dolomite & 0.008 & 142.6 & 49 & 2.87 & $2 ; 3$ \\
\hline Sum of clays & 0.648 & 33.4 & 8.5 & 2.73 & 1 \\
\hline Pyrite & 0.017 & 323.5 & 132 & 4.93 & $2 ; 3$ \\
\hline Kerogen & 0.009 & 9.5 & 3.20 & 1.25 & 3 \\
\hline
\end{tabular}

geneous mixture of water, gas with the addition of oil (Stadtmüller et al. 2018). For the shales and the calcareous formations, it was assumed $100 \%$ water saturation. Elastic parameters of fluids, which were used in modelling, are presented in Table 4.

5. Computing the density and $P$ - and $S$-wave velocities of saturated rock, $V_{p}\left(\phi, S_{\mathrm{w}}\right), V_{s}\left(\phi, S_{\mathrm{w}}\right)$, and $\varrho_{\mathrm{sat}}\left(\phi, S_{\mathrm{w}}\right)$, with the use of Eqs. (13a-c) and cross-plotting $V p / V s$ ratio versus $P$-Impedance as a function of porosity and saturation.

\section{Application of shale model}

The shale model was applied to the lower Palaeozoic deposits classified as shales in the lithology discrimination procedure (group 1). The elastic moduli for clay aggregates from Vernik and Kachanov (2010) were assumed, and the moduli for the nonclay components were taken from the literature (Table 5). The fractional volumes of matrix minerals were the same as for GEM modelling (compare Table 3). Though this model is valid for conventional shales only, the kerogen was not excluded from the matrix since its fractional volume is very low in shales from group 1.

To compute bedding-normal compressional and shear velocities (Eqs. 14 and 18), it was necessary to get the bedding-normal elastic stiffness of the solid matrix, $c_{33 \mathrm{~m}}$ (Eq. 15), and the pseudo-shape factor, $k$ (Eq. 17). The

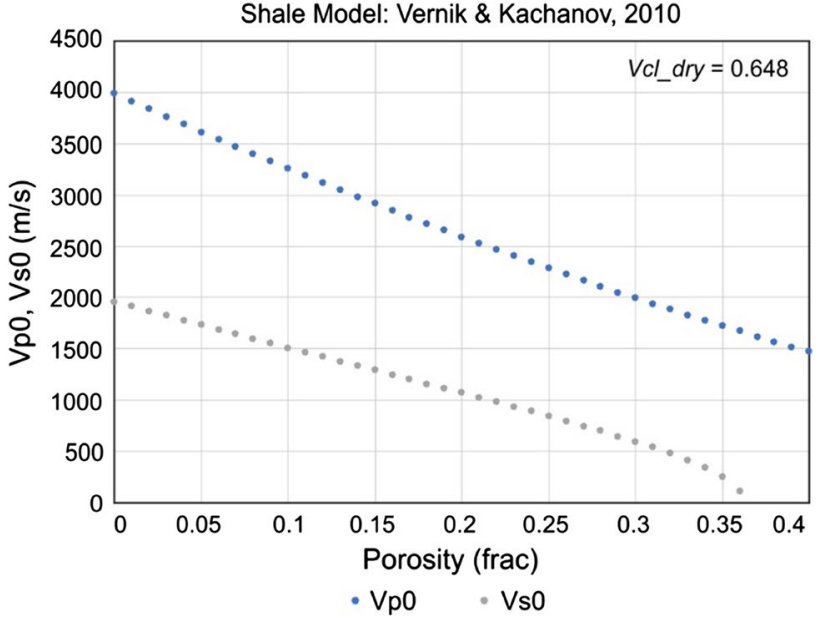

Fig. 8 Bedding-normal compressional and shear wave velocities as a function of porosity derived from the shale model of Vernik and Kachanov (2010) for dry clay volume $V_{\text {cl_dry }}=0.648$ (value for the shales from the lithological discrimination group 1)

calculations were done for $V_{\text {cl_dry }}=0.648$ (Table 5); shale matrix density was assumed as $2.73 \times 10^{3} \mathrm{~kg} / \mathrm{m}^{3}$ (as suggested in Vernik and Kachanov 2010), and the $P$-wave modulus of nonclay minerals, $M_{n \mathrm{cl}}$, was derived from the Hill average (Eq. 8) of $P$-wave moduli of individual minerals $\left(M\left(c_{33}\right)\right.$ from Table 5). Values of these parameters were as follows: $M_{n \mathrm{cl}}=95.75 \mathrm{GPa}, k=4.46$, and $c_{33 \mathrm{~m}}=43.35$ GPa. The fluid density (Eq. 15), i.e. water, was equal to 
Table 6 Effective moduli of dry rock multi-mineral frame for porosity equal to $0 \%$ (the matrix point), $K_{\mathrm{ma}}$ and $G_{\mathrm{ma}}$, and for critical porosity, $K_{\mathrm{dry}}\left(\phi_{\mathrm{c}}\right)$ and $G_{\mathrm{dry}}\left(\phi_{\mathrm{c}}\right)$, for the lithology groups and the pure carbonates

\begin{tabular}{lclll}
\hline Modulus & \multicolumn{4}{l}{ Elastic moduli (GPa) } \\
\cline { 2 - 5 } & \multicolumn{5}{c}{ (1) Shales } & $\begin{array}{l}\text { (2) Shales } \\
\text { with OM and } \\
\text { HC }\end{array}$ & $\begin{array}{l}\text { (3) Carbon- } \\
\text { ates and } \\
\text { marls }\end{array}$ & Pure carbonates \\
& \multicolumn{5}{c}{$\begin{array}{l}\text { (3) } \\
K_{\text {ma }}\end{array}$} & 40.35 & 33.09 & 47.74 & 72.78 \\
$G_{\text {ma }}$ & 28.90 & 25.63 & 30.02 & 33.03 \\
$K_{\text {dry }}\left(\phi_{\mathrm{c}}\right)$ & 0.62 & 0.56 & 2.15 & 2.37 \\
$G_{\text {dry }}\left(\phi_{\mathrm{c}}\right)$ & 0.86 & 0.79 & 2.97 & 3.17 \\
\hline
\end{tabular}

Table $7 V p / V s$ ratio and acoustic impedance values of matrix points

Parameter $V p / V s$ ratio (unitless) acoustic impedance $\times 10^{3}(\mathrm{~kg} /$ $\mathrm{m}^{3} \mathrm{~m} / \mathrm{s}$ )

\begin{tabular}{lllll}
\cline { 2 - 5 } & (1) Shales & $\begin{array}{l}\text { (2) Shales } \\
\text { with OM and } \\
\text { HC }\end{array}$ & $\begin{array}{l}\text { (3) Carbon- } \\
\text { ates and } \\
\text { marls }\end{array}$ & $\begin{array}{l}\text { Pure car- } \\
\text { bonates }\end{array}$ \\
\hline VpVs & 1.65 & 1.62 & 1.71 & 1.88 \\
AI & 14.634 & 13.241 & 15.472 & 17.898 \\
\hline
\end{tabular}

$1.05 \times 10^{3} \mathrm{~kg} / \mathrm{m}^{3}$, the same value as in GEM modelling (Table 4). Result of modelling the bedding-normal velocities with the use of the shale model is presented in Fig. 8.

\section{Discussion}

\section{Results of GEM rock physics templates}

As a result of the GEM workflow application, the effective elastic moduli of the multi-mineral matrix for each lithology group was determined as well as the elastic moduli of the dry rock frame at the critical porosity. The values are included in Table 6. The moduli obtained for the matrix of shales, shales with increased organic matter, and calcareous deposits were used for calculation of the matrix points in the domain $V p V s-\mathrm{AI}$ (Table 7). Both tables are complemented with the values obtained for the "pure carbonates" that were helpful in the analysis of the Kopalino limestone formation. It was assumed that the theoretical pure carbonates were composed of $80 \%$ of limestone and $20 \%$ of dolomite.

The rock physics templates were constructed separately for each lithology group and displayed in the $V p / V s$ ratio versus acoustic impedance cross-plot. The total porosity (PHIT) from the interpretation of well logging data was used a key colour. Figure 9 presents the results of RPT modelling of compaction trend by the lower modified Hashin-Shtrikman bound ( $\mathrm{a}$ and $\mathrm{c}$ ), and the cementation trend modelled by the upper modified Hashin-Shtrikman bound (b and d).

The analysis of the constructed rock physics templates revealed that for shales, in general, the lower modified Hashin-Shtrikman bound fits much better to the data (Fig. 9a) than the upper bound (Fig. 9b). It might be surprising at first, since the first model is recommended to unconsolidated or soft sediments, and describes the compaction process of loose deposits (e.g. Avseth et al. 2001, 2009; Avseth et al. 2010; Chi and Han 2009; Mavko et al. 2011). However, in the shales (lithology group 1), the clear and significant compaction trend is visible, as shown in Fig. 6. Additionally, the modelled porosity agrees with the total porosity from the logs.

The matrix line for shales with organic matter and hydrocarbon (lithology group 2) is shifted towards lower $V p / V s$ ratio and acoustic impedance values, which means that the addition of kerogen and hydrocarbons significantly softens the elastic properties of shales. The saturation lines only approximate the hydrocarbon saturation and do not fit perfectly to the data. A few reasons might cause it. Firstly, the hydrocarbons in organic shales are present as both absorbed and free hydrocarbons, which were not accounted for in this modelling. Secondly, the total hydrocarbon saturation was approximated and averaged using the data from all investigated wells. Thirdly, the misfit between the saturation lines and the data might be a consequence of the method used for modelling the fluid elastic properties. In this study, the simple homogenous fluid mixture (Reuss average) was assumed, while it might be more complex and heterogeneous (like patchy saturation). And finally, the anisotropic extension of the Gassmann's relation should have been used instead of its isotropic form (Brown and Korringa 1979; Thomsen 2010; Mavko et al. 2011). However, it was impossible to provide all the necessary parameters that are required in generalised Gassmann's and Brown and Korringa's equations. For all these reasons, and the fact that the shales are in general "non-Gassmann" rocks, the saturation lines should be considered only qualitatively not quantitatively and should be treated as a rough approximation of elastic properties changes caused by the hydrocarbon saturation.

RPT modelling for the calcareous deposits was done for carbonates and marls according to the results of lithology discrimination (group 3) and the corresponding elastic moduli (Table 3). Since the results were rather unsatisfactory for the Kopalino limestones (the points of the highest $V p V s$ and AI described as a group 3a in Fig. 9c, d), it was decided to model also the theoretical "pure carbonates" composed of $80 \%$ of calcite and 20\% dolomite. The RPT pure carbonate lines are presented along the lines obtained for the real deposits (Fig. 9c, d). Analysing the lines on the templates for the lithology group 3 , one may conclude that the elastic properties of marly claystones/siltstones and marls (group 3b) are very different from 
(a)

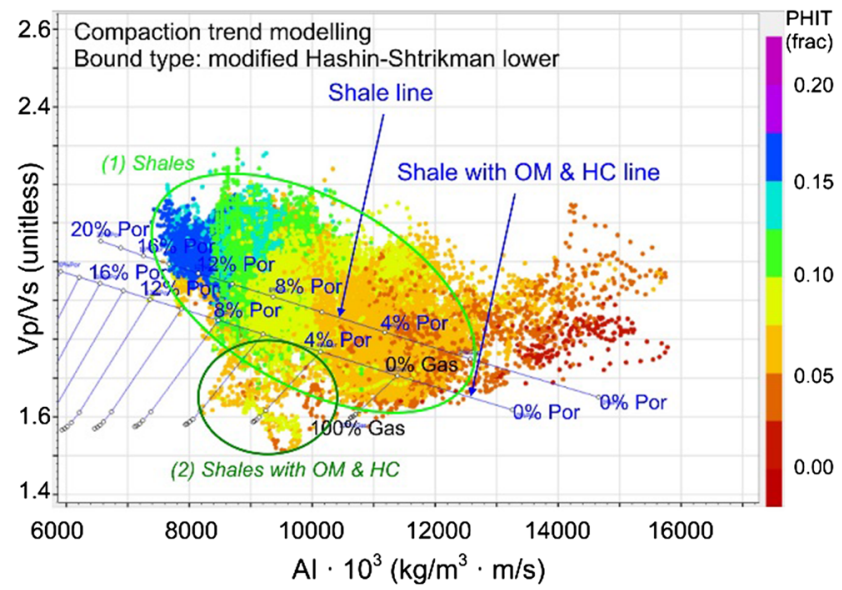

(c)

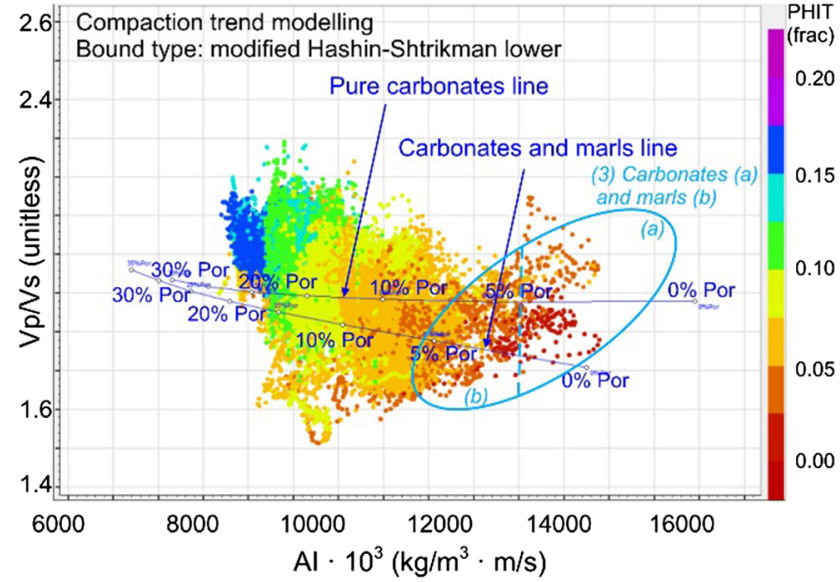

Fig. 9 Rock physics templates constructed for the shales, the shales with organic matter and hydrocarbon saturation, and the carbonates and marls; both modified Hashin-Shtrikman bounds were applied to

the elastic properties of limestones (group 3a). Marly and other calcareous deposits follow the shale trend but exhibit moderate acoustic impedance (but higher than for shales) values and lower $V p / V s$ ratios. These sediments are present mainly in the Prabuty Formation. They could be satisfactorily modelled by the compaction trend derived from the lower modified Hashin-Shtrikman bound, similar to the approach utilised for shales (Fig. 9c). The Kopalino limestones elastic properties are much better explained by the pure carbonates line, derived either from the lower or the upper modified Hashin-Shtrikman bounds. However, it seems that the cementation trend obtained from the latter slightly better fits to the data (Fig. 9d).

\section{Results of the shale model in comparison with GEM rock physics templates}

The shale model provided bedding-normal compressional and shear wave velocities, $V_{P 0}$ and $V_{S 0}$ in a function of (b)

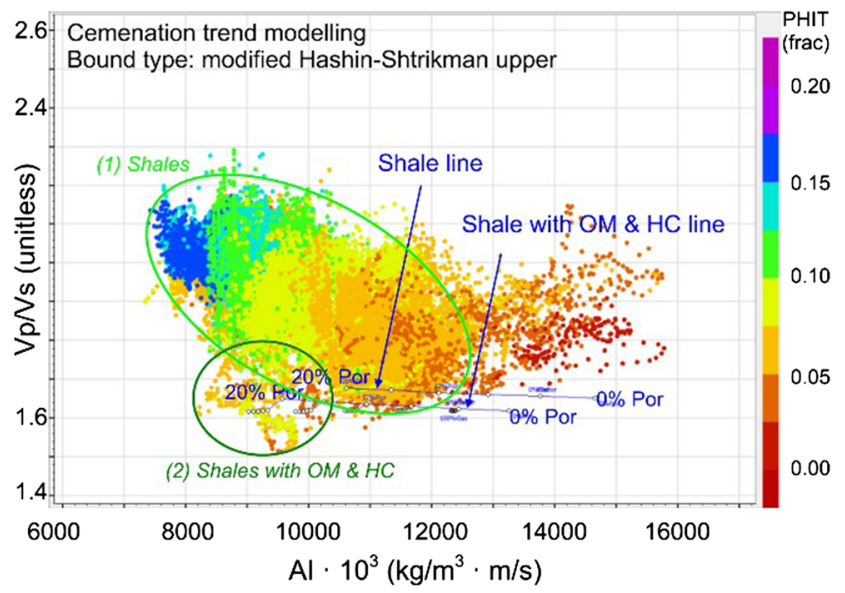

(d)

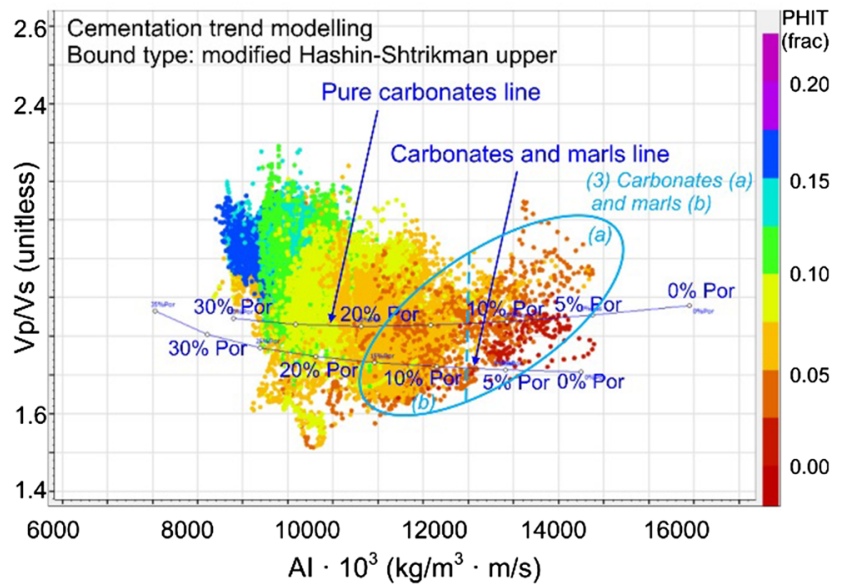

model the compaction and the cementation trends. "Por" stands for total porosity

porosity and the average dry clay volume $V_{\text {cl_dry }}=0.648$ for formations classified as shales (lithology group 1). Additionally, the bedding-normal $P$ - and $S$-wave velocities were modelled for various clay volumes: $0.2,0.4,0.6$ and 0.8 , and superimposed on the velocity-porosity cross-plots presenting well logging data (Fig. 10).

It can be seen that the GEM approach better describes velocity-porosity relation in shales from the Baltic Basin than the SM. It is observed especially for very low porosities, below $5 \%$, which are caused by higher compaction. Additional lines of the SM drawn for various clay contents show only that the vertical velocities should be lower for higher clay volume, but they do not fit to the data.

The misfit to the log data is easier to notice when the velocity-porosity cross-plot presents log data from the shale formations considered as non-perspective (Fig. 11). They are Puck, Kociewie, Pelplin, Pasłęk, and Prabuty Formations. Formations regarded as sweet spots, i.e. Jantar Member and 


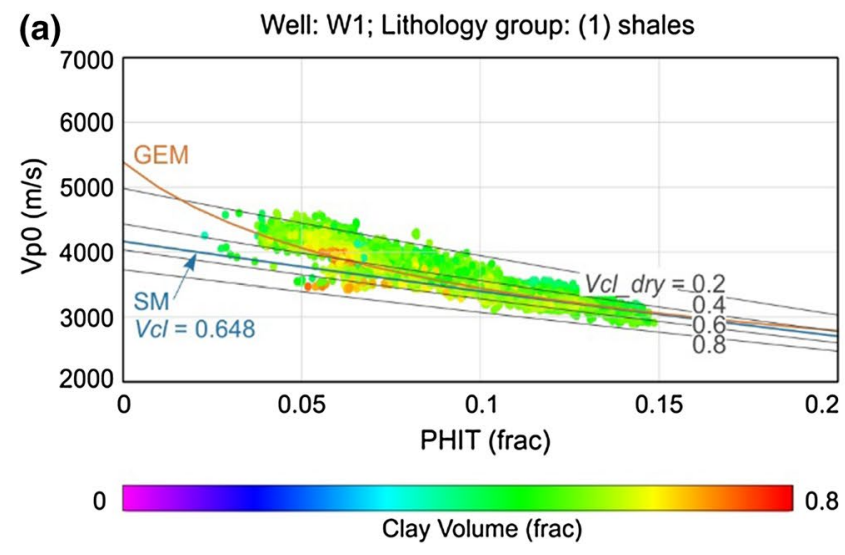

Fig. 10 Vertical velocities from sonic logs, $V_{P 0}$ (a) and $V_{S 0}$ (b), crossplotted with total porosity, PHIT-logging data for the shales (group 1) from well W1. Superimposed lines present results of RPT model-

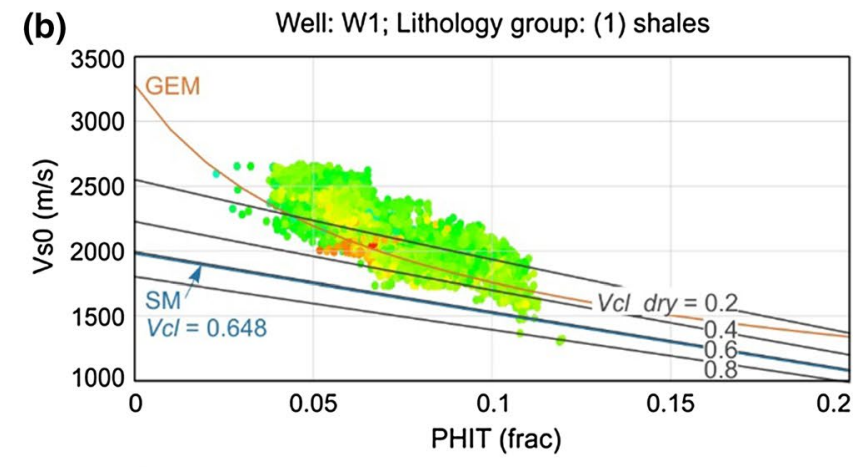

0

Clay Volume (frac)

ling with the use of GEM theory and the shale model (SM) for average dry clay volume in shales $V_{\text {cl_dry }}=0.648$ (lithology group 1), as well as for theoretical dry clay volumes: $V_{\text {cl_dry }}=0.2,0.4,0.6$, and 0.8 (a)

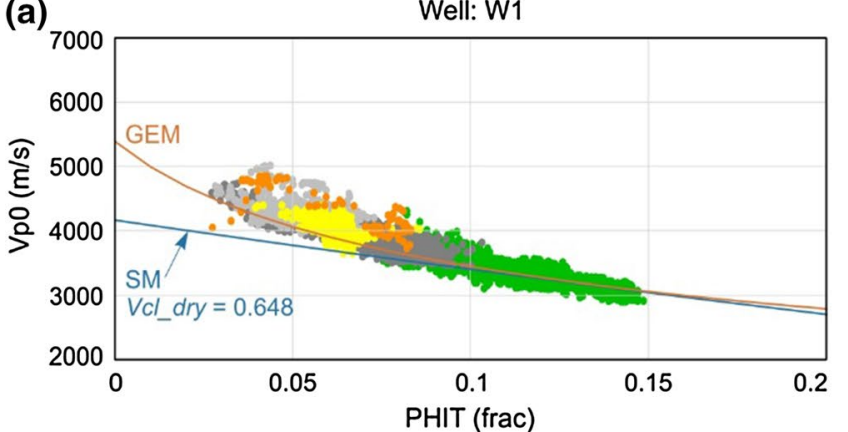

(b)

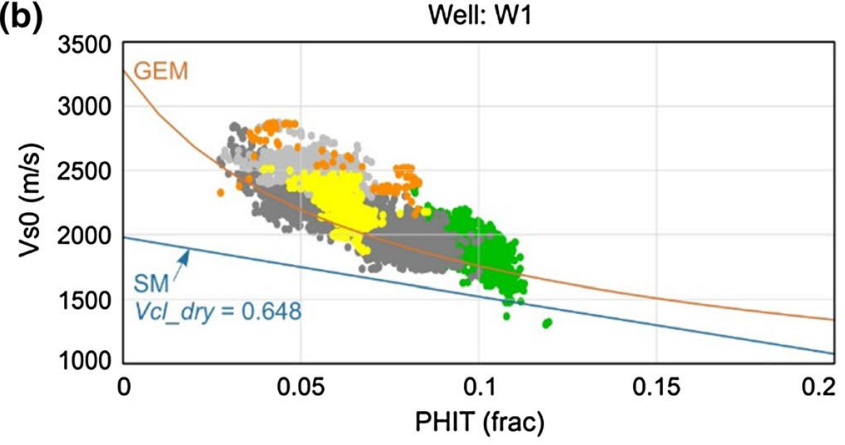

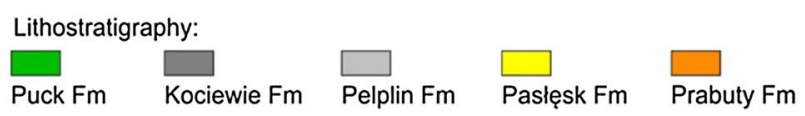

Fig. 11 Vertical velocities from sonic $\operatorname{logs}, V_{P 0}(\mathbf{a})$ and $V_{S 0}(\mathbf{b})$, cross-plotted with total porosity, PHIT in comparison with the GEM modelling and the SM results-logging data for non-perspective shale formations from well W1

Sasino Formation, are excluded from this cross-plot. The shale model agrees with the GEM results and fits the data only for compressional wave velocity and for less compacted formations (Puck and Kociewie Formations). For shear wave velocity, it hardly follows the compaction trend.

The results of the RPT obtained from the GEM and the SM were also compared with the $V p / V s$ ratio-AI domain (Fig. 12). Figure 12a and b presents the same data, but the two different parameters are used as a colour scale: clay volume (a) and total porosity (b). The SM incorrectly models the elastic properties of the shale formations. It gives much higher $V p / V s$ ratio than the GEM model and also much higher than the measurements (i.e. well logging data). It also predicts the wrong values of $P$-impedance (AI) and its changes with porosity.

\section{Conclusions}

To sum up the results, the final rock physics template for lower Paleozoic formations from the Baltic Basin may be composed of separate lines for various lithologies derived from GEM modelling as follows (Fig. 13):

- the shale line that models the compaction trend,

- the shale with organic matter and hydrocarbons that models the compaction trend and hydrocarbon saturation,

- the marls trend that models the compaction trend,

- the carbonates trend that models the cementation trend. 


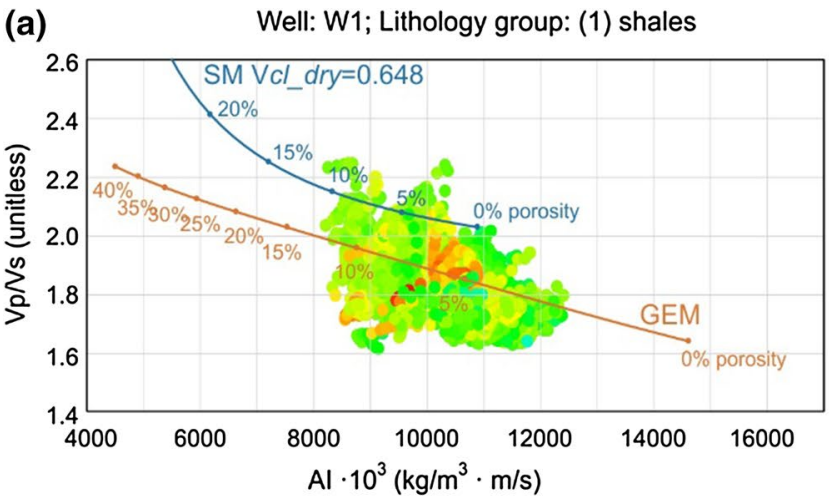

0

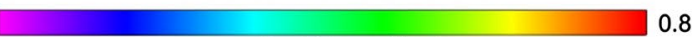

Clay Volume (frac) (b) Well: W1; Lithology group: (1) shales
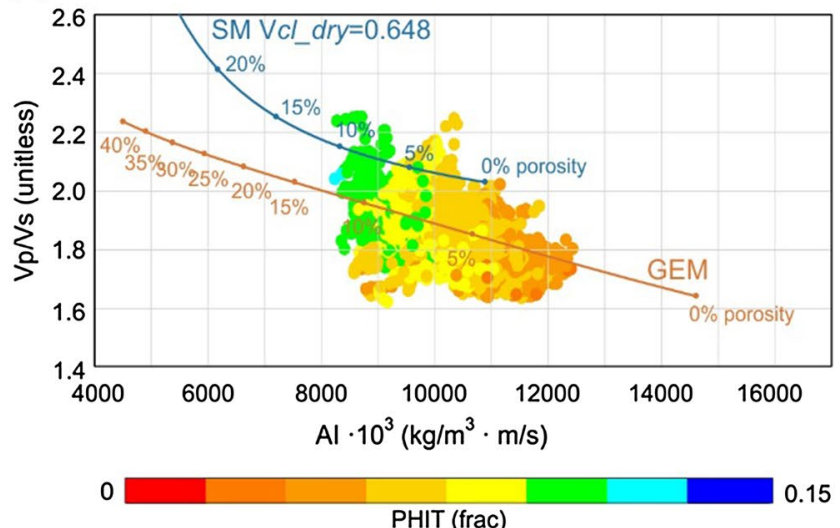

Fig. 12 Results of GEM and SM prediction of elastic properties in the $V p / V s$ ratio-acoustic impedance (AI) domain and as a function of clay volume (a) and total porosity PHIT (b) - logging data for the shales (group 1) from well W1

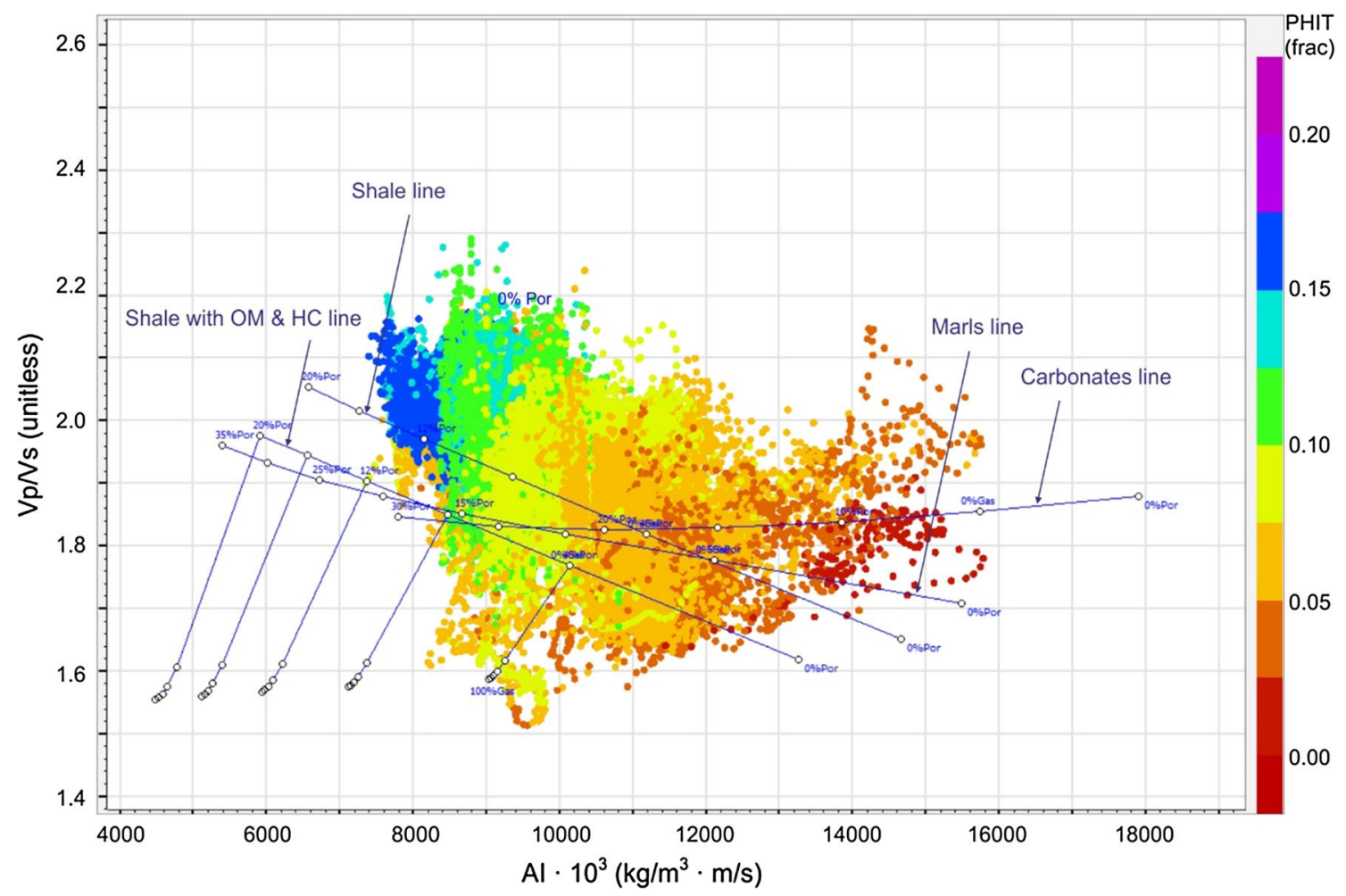

Fig. 13 Final rock physics template created for the lower Paleozoic formations from the Baltic Basin, Poland

\section{Summary}

In the paper, the analyses of the elastic properties of the Silurian and Ordovician formation from the Baltic Basin were presented. The logs measured in three closely located three wells were utilised in the rock physics modelling. Using the results of petrophysical formation evaluation, the lithology discrimination was made. Three lithology groups were determined with the use of the criteria defined by the cutoff. They were: (1) shales, (2) shales with increased organic matter content and saturated with hydrocarbons (organic shales), and (3) carbonates, marls, and other calcareous sediments, such as marls or marly claystones/mudstones. Then, the average mineral composition of the matrix for each lithology group was derived. It was crucial information that allowed computing the effective moduli of the skeleton, 
which represented the matrix elastic properties of the whole lithology group.

Additionally, the methodology and the workflow of creating rock physics templates for lower Paleozoic shale formation were proposed. The effective medium theory, the mixing laws, and the contact grain model were utilised in the granular effective medium approach, as well as the semiempirical relation between velocities and porosity in the shale model. As a result of the first method, the effective elastic moduli of dry rock frame at $0 \%$ porosity (i.e. of the matrix) and the dry rock frame at critical porosity were computed and presented for each lithology group. They were obtained from the Hashin-Shtrikman-Walpole bounds and the Hertz-Mindlin contact theory, respectively. The modified Hashin-Shtrikman bounds allowed modelling the compaction and the cementation trends, while the Gassmann's relation was used for saturated rock elastic moduli computation and fluid substitution. The second approach provided vertical (or bedding-normal) $P$ - and $S$-wave velocities in a function of total porosity and dry clay volume, which were transformed also into $\mathrm{Vp} / \mathrm{Vs}$ ratio-AI domain.

Created rock physics templates showed that the formations that were considered as shale, here: claystones, mudstones, and siltstones, exhibited elastic behaviour that was satisfactorily described by the compaction trend from GEM modelling: the deeper the formation was, the better the elastic properties were. Addition of carbonate minerals in marls, marly claystones/mudstones, or other fine-grained sediments caused further increase in acoustic impedance, but the compaction trend observed in shales was generally followed. The compaction trend was obtained from the lower modified Hashin-Shtrikman bound that is used in uncemented or soft sands rock physics models. It might be surprising that such model satisfactory described the elastic behaviour of highly compacted shales. However, the data for shales fit very well to the upper and the lower elastic bounds of a mixture of quartz and water. What is more, the data presented in the $V p V s-\mathrm{AI}$ cross-plot, confirmed distinct and very clear compaction.

Different behaviours were observed for the Kopalino limestone formation distinguished from the carbonates and marls lithology group. Here, the elastic properties were slightly better described by the cementation trend. The abundance of the carbonate minerals caused the increase in both acoustic impedance and $V p / V s$ ratio values, unlike in shales, calcareous shales, and marls. Additionally, very low porosity was observed for the limestone that was correctly predicted by the applied rock physics model.

The shale model, though regarded as universal, did not satisfactorily predict the elastic properties of shales, especially for low porosities and strongly compacted deposits.

In the end, the final rock physics template was proposed that can be useful in elastic properties determination of the lower Paleozoic formation from the Baltic Basin in Poland. Further research of elastic modelling of shales, especially of organic shales, is in progress. They are focused on anisotropy and the influence of organic matter.

Acknowledgements Data were allowed by the Polish Oil and Gas Company, Warsaw, Poland, for the research conducted during the Blue Gas program 2013-2017: "Methodology to determine sweet spots based on geochemical, petrophysical and geomechanical properties in connection with correlation of laboratory tests with well logs and generation model 3D-(MWSSSG) Polskie Technologie dla Gazu Łupkowego" financed by the National Centre for Research and Development, Poland. Techlog software and Hampson-Russell software were used thanks to the AGH University of Science and Technology grants. Paper was presented at the CAGG 2019 Conference "Challenges in Applied Geology and Geophysics" organised at the AGH University of Science and Technology, Krakow, Poland, 10-13 September 2019. Paper was financially supported from the research subsidy no 16.16.140.315 at the Faculty of Geology Geophysics and Environmental Protection of the AGH University of Science and Technology, Krakow, Poland, 2019.

Open Access This article is distributed under the terms of the Creative Commons Attribution 4.0 International License (http://creativeco mmons.org/licenses/by/4.0/), which permits unrestricted use, distribution, and reproduction in any medium, provided you give appropriate credit to the original author(s) and the source, provide a link to the Creative Commons license, and indicate if changes were made.

\section{References}

Alford RM (1986) Shear data in the presence of azimuthal anisotropy. In: SEG technical program expanded abstracts 1986, pp 476-479. https://doi.org/10.1190/1.1893036

Allo F (2019) Consolidating rock-physics classics: a practical take on granular effective medium models. Lead Edge 38(5):334-340. https://doi.org/10.1190/tle38050334.1

Avseth P (2014) Geological processes and rock physics signature of upper jurassic organic-rich shales, Norwegian shelf. In: 76th EAGE conference and exhibition-workshops, extended abstracts, pp WS12-A05. https://doi.org/10.3997/2214-4609.20140596

Avseth P, Carcione JM (2015) Rock-physics analysis of clay-rich source rocks on the Norwegian shelf. Lead Edge 34(11):1340 1342,1344-1348. https://doi.org/10.1190/tle34111340.1

Avseth P, Mavko G, Dvorkin J, Mukerji T (2001) Rock physics and seismic properties of sands and shales as a function of burial depth. In: SEG technical program expanded abstracts 2001, pp 1780-1783. https://doi.org/10.1190/1.1816471

Avseth P, Jørstad A, van Wijngaarden A, Mavko G (2009) Rock physics estimation of cement volume, sorting, and net-to-gross in North Sea sandstones. Lead Edge 28(1):98-108. https://doi. org/10.1190/1.3064154

Avseth P, Mukerji T, Mavko G (2010) Quantitative seismic interpretation: Applying rock physics tools to reduce interpretation risk. Cambridge University Press, New York

Ba J, Cao H, Carcione J, Tang G, Yan XF, Sun WT, Nie JX (2013) Multiscale rock physics templates for gas detection in carbonate reservoir. J Appl Geophys 93:77-82. https://doi.org/10.1016/j. jappgeo.2013.03.011

Bała M (2007) Effects of shale content, porosity and water- and gassaturation in pores on elastic parameters of reservoir rocks based 
on theoretical models of porous media and well-logging data (in Polish with English summary). Prz Geol 55(1):46-55

Bała M (2015) Determination of elastic parameters of organic shales specified on the basis of theoretical relationships of BiotGassmann and Kuster-Toksöz (in Polish with English summary). Nafta-Gaz 12:1005-1016. https://doi.org/10.18668/NG2015.12.09

Bała M (2017) Characteristics of elastic parameters determined on the basis of well logging measurements and theoretical modeling, in selected formations in boreholes in the Baltic Basin and the Baltic offshore (in Polish with English summary). Nafta-Gaz 8:558-570. https://doi.org/10.18668/NG.2017.08.03

Bała M, Cichy A, Wasilewska-Błaszczyk M (2019) Attempts to calculate the pseudo-anisotropy of elastic parameters of shale gas formations based on well logging data and their geostatistical analysis. Geol Geophys Environ 45(1):5-20. https://doi.org/10.7494/ geol.2019.45.1.5

Berryman JG (1995) Mixture theories for rock properties. In: Ahrens TJ (ed) Rock physics and phase relations: a handbook of physical constants. Am Geophys Un, Washington, DC, pp 205-228

Bredesen K, Avseth P, Johansen TA, Olstad R (2019) Rock physics modelling based on depositional and burial history of Barents Sea sandstones. Geophys Prospect 67(1):825-842. https://doi. org/10.1111/1365-2478.12683

Brie A, Endo T, Codazzi D, Esmersoy C, Hsu K, Denoo S, Mueller MC, Plona T, Shenoy R, Sinha B (1998) The new directions in sonic logging. Oilfield Rev 10(1):40-55

Brown RJS, Korringa J (1979) On the dependence of the elastic properties of a porous rock on the compressibility of the pore fluid. Geophysics 40(4):608-616. https://doi.org/10.1190/1.1440551

Carcione JM, Avseth P (2015) Rock-physics templates for clayrich source rocks. Geophysics 80(5):D481-D500. https://doi. org/10.1190/GEO2014-0510.1

Carcione JM, Helle HB, Avseth P (2011) Source-rock seismicvelocity models: Gassmann versus Backus. Geophysics 76(5):N37-N45

Carmichael RS (1989) Practical handbook of physical properties of rocks and minerals. CRC Press, Boca Raton, FL

Chi XG, Han DH (2009) Lithology and fluid differentiation using a rock physics template. Lead Edge 28(1):60-65. https://doi. org/10.1190/1.3064147

Cyz M, Mulińska M, Pachytel R, Malinowski M (2018) Brittleness prediction for the lower Paleozoic shales in Northern Poland. Interpretation 6(3):SH13-SH23. https://doi.org/10.1190/ INT-2017-0203.1

Dræge A (2019) Geo-consistent depth trends: honoring geology in siliciclastic rock-physics depth trends. Lead Edge 38(5):379-384. https://doi.org/10.1190/tle38050379.1

Esmersoy C, Koster K, Williams M, Boyd A, Kane M (1994) Dipole shear anisotropy logging. In: SEG technical program expanded abstracts 1994, pp 1139-1142. https://doi.org/10.1190/1.1822720

Feldman-Olszewska A, Roszkowska-Remin J (2016) Lithofacies of the Ordovician and Silurian formations prospective for shale gas/ oil in the Baltic and Podlasie-Lublin areas (in Polish with English summary). Prz Geol 64(12):968-975

Gajek W, Malinowski M, Verdon JP (2018) Results of downhole microseismic monitoring at a pilot hydraulic fracturing site in PolandPart 2: S-wave splitting analysis. Interpretation 6(3):SH49-SH58. https://doi.org/10.1190/INT-2017-0207.1

Gegenhuber N, Pupos J (2015) Rock physics template from laboratory data for carbonates. J Appl Geophys 114:12-18. https://doi. org/10.1016/j.jappgeo.2015.01.005

CGG (2015) Hampson-Russell Software. Version HRS10.3: Interactive Help. CGG, Calgary, Alberta

Hertz H (1882) Über die Berührung fester elastischer Körper. Journal für die reine und angewandte Mathematik 92(1):156-171
Jarzyna JA, Wawrzyniak-Guz K (ed) et al (2017b) Adaptation of the Polish conditions of the methodologies of the sweet spots determination on the basis of correlation of well logging with drilled core samples: methodology to determine sweet spots based on geochemical, petrophysical and geomechanical properties in connection with correlation of laboratory test with well logs and generation model 3D (in Polish). Drukarnia Goldruk Wojciech Gołakowski, Kraków

Jarzyna JA, Bała M, Krakowska PI, Puskarczyk E, Strzępowicz A, Wawrzyniak-Guz K, Więcław D, Ziętek J (2017a) Shale gas in Poland. In: Al-Megren HA, Altamimi RH (ed) Advances in natural gas emerging technologies. IntechOpen, https://www.intec hopen.com/books/advances-in-natural-gas-emerging-technologi es/shale-gas-in-poland. https://doi.org/10.5772/67301

Jarzyna JA, Krakowska PI, Puskarczyk E, Wawrzyniak-Guz K, Zych M (2018) Petrophysical characteristics of the shale gas formations in the Baltic Basin, Northern Poland. In: Kovacs F, Takasc G, Fkoanyi L (ed) Geoscience and engineering: a publication of the University of Miskolc. 6(9):9-18

Johnston JE, Christensen NI (1995) Seismic anisotropy of shales. J Geophys Res-Sol Ea 100(B4):5991-6003. https://doi. org/10.1029/95JB00031

Kotarba MJ, Lewan MD, Więcław D (2014) Shale gas and oil potential of Lower Palaeozoic strata in the Polish Baltic Basin by hydrous pyrolysis. In: 4th EAGE shale workshop. Shales: what do they have in common? Mo P02. https://doi.org/10.3997/22144609.20140022

Krakowska PI, Puskarczyk E (2015) Tight reservoir properties derived by nuclear magnetic resonance, mercury porosimetry and computed microtomography laboratory techniques. Case study of palaeozoic clastic rocks. Acta Geophys 63(3):789-814. https://doi. org/10.1515/acgeo-2015-0013

Kuster GT, Toksöz MN (1974) Velocity and attenuation of seismic waves in two-phase media: Part I. Theoretical formulations. Geophysics 39(5):587-606. https://doi.org/10.1190/1.1440450

Kwietniak A, Cichostępski K, Pietsch K (2018) Resolution enhancement with relative amplitude preservation for unconventional targets. Interpretation 6(3):SH59-SH71. https://doi.org/10.1190/ INT-2017-0196.1

Li Y (2006) An empirical method for estimation of anisotropic parameters in clastic rocks. Lead Edge 25(6):706-711. https://doi. org/10.1190/1.2210052

Li Y, Guo ZQ, Liu C, Li XY, Wang G (2015) A rock physics model for the characterization of organic-rich shale from elastic properties. Pet Sci 12(2):264-272. https://doi.org/10.1007/s1218 2-015-0029-6

Liana B, Papiernik B (2017) Natural and drilling induced factors influencing the brittleness estimation based on sonic logs. SGEM Conf Proc 17(14):741-748

Malinowski M, Jarosinski M, Krzywiec P, Pasternacki A, WawrzyniakGuz K (2018) Introduction to special section: characterization of potential lower Paleozoic shale resource play in Poland. Interpretation 6(3):SH1-SH2. https://doi.org/10.1190/int-2018-0613-spsei ntro. 1

Mavko G, Mukerji T, Dvorkin J (2011) Rock physics handbook. Tools for seismic analysis of porous media, 2nd edn. Cambridge University Press, New York

Mindlin RD (1949) Compliance of elastic bodies in contact. J Appl Mech 16:259-268

Modliński Z, Szymański B (1997) The ordovician lithostratigraphy of the peribaitic depression (NE Poland). Geol Q 41(3):273-288

Modliński Z, Szymański B, Teller L (2006) The silurian lithostratigraphy of the polish part of the peri-baltic depression (N Poland) (in Polish). Prz Geol 54(9):787-796

Mur A, Vernik L (2019) Testing popular rock-physics models. Lead Edge 38(5):350-357. https://doi.org/10.1190/tle38050350.1 
Narongsirikul S, Haque Mondol N, Jahren J (2019) Acoustic and petrophysical properties of mechanically compacted overconsolidated sands: part 2-rock physics modelling and application. Geophys Prospect 67(1):114-127. https://doi. org/10.1111/1365-2478.12692

Nur A (1992) Critical porosity and the seismic velocities in rocks. EOS Trans Am Geophys Un 73:43-66

Nye JF (1985) Physical Properties of Crystals: Their Representation by Tensor and Matrices. Oxford University Press, Oxford

Ødegaard E, Avseth P (2004) Well log and seismic data analysis using rock physics templates. First Break 22(10):37-43. https://doi. org/10.3997/1365-2397.2004017

Passey QR, Creaney S, Kulla JB, Moretti FJ, Stroud JD (1990) A practical model for organic richness from porosity and resistivity logs. AAPG Bull 74(12):1777-1794

Podhalańska T (2016) Block of articles - Unconventional hydrocarbon systems of the Baltic-Podlasie-Lublin basins and the carboniferous basin of SW Poland; prospects for the occurrence of unconventional hydrocarbon deposits-preliminary word (in Polish with English summary). Prz Geol 64(12):951-952

Podhalańska T, Waksmundzka MI, Becker A, Roszkowska-Remin J (2016) Investigation of the prospective areas and stratigraphic horizons of the unconventional hydrocarbon resources in Poland - new results and future research directions (in Polish with English summary). Prz Geol 64(12):953-962

Poprawa P (2010) Shale gas potential of the lower Paleozoic complex in the Baltic and Lublin-Podlasie basins (Poland) (in Polish with English summary). Prz Geol 58(3):226-249

Porębski SJ, Prugar W, Zacharski J (2013) Silurian shales of the East European platform in Poland-some exploration problems. Prz Geol 61(8):468-477

Prasad M, Pal-Bathija A, Johnston M, Rydzy M, Batzle M (2009) Rock physics of the unconventional. Lead Edge 28(1):34-38. https:// doi.org/10.1190/1.3064144

Reuss A (1929) Berechnung der Fliessgrenze von Mischkristallen auf Grund der Plastizitätsbedingung für Einkristalle. Z Angew Match Mech 9(1):49-58. https://doi.org/10.1002/zamm.19290090104

Sayers CM (1994) The elastic anisotropy of shales. J Geophys Res-Sol Ea 99(B1):767-774. https://doi.org/10.1029/93JB02579

Sayers CM (2005) Seismic anisotropy of shales. Geophys Prospect 53(5):667-676. https://doi.org/10.1111/j.1365-2478.2005.00495.x

Sayers CM (2013) The effect of kerogen on the elastic anisotropy of organic-rich shales. Geophysics 78(2):D65-D74. https://doi. org/10.1190/geo2012-0309.1

Sayers CM, Dasgupta S (2019) A predictive anisotropic rock-physics model for estimating elastic rock properties of unconventional shale reservoirs. Lead Edge 38(5):358-365. https://doi. org/10.1190/tle38050358.1

Sayers CM, den Boer LD (2016) The elastic anisotropy of clay minerals. Geophysics 81(5):C193-C203. https://doi.org/10.1190/geo20 16-0005.1

Schön J (1996) Physical properties of rocks: fundamentals and principles of petrophysics. Elsevier, Oxford

Sengupta M, Katahara K, Smith N, Kittridge M, Blangy JP (2015) Modeling anisotropic elasticity in an unconventional reservoir.
Lead Edge 34(11):1332-1338. https://doi.org/10.1190/tle3411133 2.1

Sikorska-Jaworowska M, Kuberska M, Kozłowska A (2016) Petrography and mineralogy of the lower Paleozoic shales from East European Craton and carboniferous sandstones from the basement of the Fore-Sudetic Homocline (in Polish with English summary). Prz Geol 64(12):963-967

Stadtmüller M, Lis-Śledziona A, Słota-Valim M (2018) Petrophysical and geomechanical analysis of the Lower Paleozoic shale formation, North Poland. Interpretation 6(3):SH91-SH106. https://doi. org/10.1190/INT-2017-0193.1

Thomsen L (1986) Weak elastic anisotropy. Geophysics 51(10):19541966. https://doi.org/10.1190/1.1442051

Thomsen L (2010) On the fluid dependence of rock compressibility: Biot-Gassmann refined. In: SEG technical program expanded abstracts 2010, pp 2447-2451. https://doi.org/10.1190/1.3513346

Thomsen L (2012) On the use of isotropic parameters $\lambda$, E, $v$ to understand anisotropic shale behaviour. In: International geophysical conference and oil and gas exhibition, Istanbul, Turkey, pp 1-4. https://doi.org/10.1190/IST092012-001.90

Tucovic N, Gegenhuber N (2017) Well-log based rock physics template of the Vienna Basin and the underlaying Calcareous Alps. Acta Geophys 65(3):441-451. https://doi.org/10.1007/s1160 0-017-0037-6

Vernik L (1993) Microcrack-induced versus intrinsic elastic anisotropy in mature HC-source shales. Geophysics 58(11):1703-1706. https ://doi.org/10.1190/1.1443385

Vernik L (2016) Seismic Petrophysics in Quantitative Interpretation. SEG, Tulsa

Vernik L, Kachanov M (2010) Modeling elastic properties of siliciclastic rocks. Geophysics 75(6):E171-E182. https://doi. org/10.1190/1.3494031

Vernik L, Liu X (1997) Velocity anisotropy in shales: a petrophysical study. Geophysics 62(2):521-532. https://doi.org/10.1190/1.14441 62

Vernik L, Milovac J (2010) Rock physics of organic shales. Lead Edge 30(3):318-323. https://doi.org/10.1190/1.3567263

Vernik L, Nur A (1992) Ultrasonic velocity and anisotropy of hydrocarbon source rocks. Geophysics 57(5):727-735. https://doi. org/10.1190/1.1443286

Voigt W (1910) Lehrbuch der Kristallphysik. Teubner, Leipzig

Wang Z (2002) Seismic anisotropy in sedimentary rocks, part 2: laboratory data. Geophysics 67(5):1423-1440. https://doi. org/10.1190/1.1512743

Wawrzyniak-Guz K (2018) Instantaneous attributes applied to full waveform sonic log and seismic data in integration of elastic properties of shale gas formations in Poland. E3S Web Conf 35:03007. https://doi.org/10.1051/e3sconf/20183503007

Xu S, Payne MA (2009) Modeling elastic properties in carbonate rocks. Lead Edge 29(1):66-74. https://doi.org/10.1190/1.3064148

Zhao L, Qin X, Han D, Geng J, Yang Z, Cao H (2016) Rock-physics modeling for the elastic properties of organic shale at different maturity stages. Geophysics 81(5):D527-D541. https://doi. org/10.1190/geo2015-0713.1 